\title{
Dendrimers as Powerful Building Blocks in Central Nervous System Disease: Headed for Successful Nanomedicine
}

\section{Victoria Leiro, Sofia Duque Santos, Cátia D. F. Lopes, Ana Paula Pêgo}

\author{
V. Leiro, S. D. Santos, C. D. F. Lopes, A. P. Pêgo \\ i3S - Instituto de Investigação e Inovação em Saúde \\ Universidade do Porto \\ Rua Alfredo Allen 208, 4200-135 Porto, Portugal \\ E-mail:apego@ineb.up.pt \\ V. Leiro, S. D. Santos, C. D. F. Lopes, A. P. Pêgo \\ INEB - Instituto de Engenharia Biomédica \\ Universidade do Porto \\ Rua Alfredo Allen 208, 4200-135 Porto, Portugal \\ C. D. F. Lopes \\ FMUP - Faculdade de Medicina da Universidade do Porto \\ Alameda Prof. Hernâni Monteiro \\ 4200-319 Porto, Portugal

\section{A. P. Pêgo} \\ ICBAS - Instituto de Ciências Biomédicas Abel Salazar \\ Universidade do Porto \\ R. Jorge de Viterbo Ferreira 228, 4050-343 Porto, Portugal \\ A. P. Pêgo \\ FEUP - Faculdade de Engenharia \\ Universidade do Porto \\ Porto, R. Dr. Roberto Frias s/n, 4200-465 Porto, Portugal
} Originally published in Advanced Functional Materials. 2018, 28, 1700313.
https://doi.org/10.1002/adfm.201700313

"This is the peer reviewed version of the following article: Leiro, Victoria \& Santos, Sofia \& Lopes, Cátia \& Pego, Ana Paula. (2017). Dendrimers as Powerful Building Blocks in Central Nervous System Disease: Headed for Successful Nanomedicine. Advanced Functional Materials. 28. 10.1002/adfm.201700313., 
which has been published in final form at https://doi.org/10.1002/adfm.201700313. This article may be used for non-commercial purposes in accordance with Wiley Terms and Conditions for Use of SelfArchived Versions."

\begin{abstract}
Dendrimers have emerged as a powerful class of nanomaterials in the nanomedicine field due to their unique structural features: globular, well - defined, highly branched and controllable structure, nanosize - scale, low polydispersity, and the presence of several terminal groups that can be functionalized with different ligands simulating the multivalency present in different biological systems. Although in its infancy, the application of dendrimers as therapeutics or theranostic tools in central nervous system (CNS) disorders is already significant and has opened promising avenues in the treatment of many conditions where the inherent "smartness" of the dendritic structures is being explored to effectively target the CNS. Here we present an overview of the past and future challenges of the use of dendrimers to respond to one of the ultimate challenges in the (nano)medicine field: to attain CNS repair and regeneration.
\end{abstract}

Keywords: blood-brain-barrier (BBB), cell targeting, dendrimers, neurological diseases, neurodegenerative diseases, surface functionalization

\title{
1. Considerations on Neurological Diseases
}

According to the World Health Organization $(\mathrm{WHO})_{1} 1$ it is estimated that 1 billion people worldwide are affected by a neurological disorder and, among these, 6.8 million people die every year as a result of these conditions.

Central nervous system (CNS) disorders currently represent $7 \%$ of the global burden of disease when measured in disability-adjusted life-years (DALY) and, as the population ages, this is expected to rise.2 Pathologies of the CNS include vascular disorders such as ischemic stroke, structural disorders like spinal cord injury ( $\mathrm{SCl}$ ); infections such as meningitis; functional disorders such as migraines; and neurodegeneration such as Alzheimer's disease (AD). The common issue among them is the resulting neurological debilitation that typically occurs, reflecting to a high extent the limited capacity for the CNS to repair itself, especially at older ages.3 An injured neuron, either sensory, motor or interneuron, engages in an abnormal pathway that is difficult to overcome. The mechanism of neuronal dysfunction resulting from a trauma, neuronal degeneration, or demyelination, may involve alterations in ion channel activity, an imbalance in the membrane potential, oxidative stress, impaired mitochondrial function, cessation of neuronal communication, and ultimately death. 4

\section{Overcoming Biological Barriers}

The early identification and diagnosis of a neuropathological status, as well as the protection and the recovery of the neuron and non - neuronal cell population has been for long a critical challenge. 
Nevertheless, the identification of CNS biomarkers of disease and cell - related therapeutic molecules has tremendously increased over the past few years, which has led to another quest for the effective delivery of these therapeutic/diagnosis molecules to the afflicted neuronal and non neuronal cells in a safe and controlled manner, as well as the fine - tuning of the delivery profiles of therapeutics in a neuropathological scenario. This is extremely challenging because from the moment a therapeutic/diagnosis agent is administered until it reaches the target injured CNS cell, several barriers have to be overcome.

The main and most - studied barrier is the blood - brain barrier (BBB). The BBB, also known as the neurovascular unit, is composed of brain capillary endothelial cells in association with astrocytes and pericytes, which together regulate relentlessly the bidirectional transfer of essential substances, while blocking the passage of harmful and foreign substances from the bloodstream to the CNS.5 Molecules can cross the BBB by paracellular (i.e., between cells) or transcellular (i.e., across cells) diffusion. Because of the tight BBB junctions, paracellular diffusion does not occur to a great extent. For transcellular diffusion, different mechanisms are in place: $a$ ) receptor - mediated endocytosis; $b$ ) carrier/transporter - mediated endocytosis; c) adsorptive or fluid - phase endocytosis; and d) passive diffusion. $6 \mathrm{It}$ is recognized that the ability to enter the brain and the mechanism adopted are dependent on the molecule size, charge, and hydrophilicity. Only highly lipophilic molecules with a low molecular weight can passively diffuse across the brain capillary endothelial cells, while most of the high molecular weight and hydrophilic molecules cannot passively cross the BBB.7 Adsorptive mediated endocytosis contributes to the transport of positively charged substances, i.e., cationic molecules.8 For carrier/transporter - mediated endocytosis, a form of facilitated diffusion, a molecule binds to a transporter on one side of the membrane resulting in the transport of the substance to the other side of the membrane, from high to low concentration. The receptor mediated mechanism presumes the involvement of specific receptors expressed on the endothelial cells of the BBB.7

Various strategies have been developed to enhance the ability of different compounds, otherwise excluded from the nervous tissue, to cross the BBB and enter the CNS when administered intravenously (i.v.).9 These can be divided into physiological methods, invasive techniques, nanomedicine approaches, or even combinatorial strategies. As a physiological approach, the receptor - mediated delivery has been more explored where a specific ligand targeted to a particular receptor of the BBB is directly associated to the delivery molecule, significantly improving its entry into the CNS.10 Nanomedicine approaches take advantage of nanomaterials to serve as vectors for the agent of interest. Invasive approaches, like the disruption of the BBB by focused ultrasound, is a promising possibility, 11 but its use must be carefully controlled to assure that the effect is transient and short in time so that it does not significantly increase the entry of plasma proteins and neurotoxic molecules, which may damage neuronal cells. Interestingly, in some CNS disorders, like stroke, the BBB is actually open in the area of the lesion in the aftermath of the insult12 for a period that can range from hours to a few days, which provides a natural window of opportunity for drug delivery. This is also the case in conditions that lead to an increased permeability of the BBB in the affected areas, such as sites of inflammation, infection, or tumors. In the latter case, the BBB is compromised for longer periods of time.

An alternative to circumvent the BBB is to adjust the route of administration. There are various possibilities to administer a therapeutic drug in the body, which may occur locally or peripherally to

INSTITUTO DE INVESTIIGAÇÃO E INOVAÇÃO EM SAÚDE UNIVERSIDADE DO PORTO

Rua Alfredo Allen, 208 4200-135 Porto Portugal +351220408800 
the intended target tissue/cell. However, there are always limitations associated to the procedure, as depicted in Figure 1.

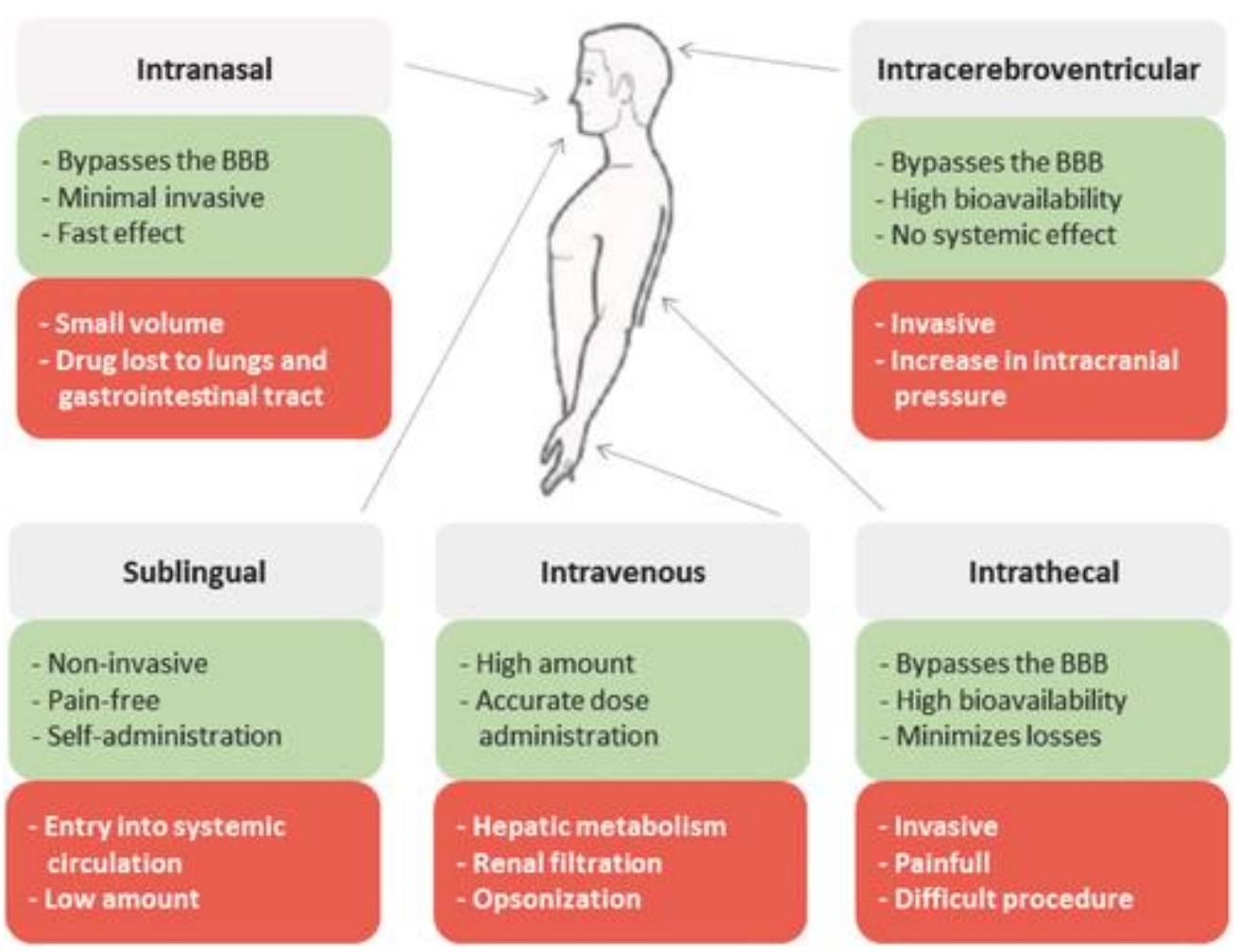

Figure1. Selected administration routes for dendrimers and other nanoparticles. The main advantages associated with each procedure are depicted in the green box and the main disadvantages in the red box

The choice of the administration route has a profound effect not only on the accessibility of the drug to the target tissue/cell but also on its time of action and efficacy. To bypass the BBB there are various options such as an intracerebral (i.c.), subarachnoid, intraparenchymal, intrathecal, or intranasal delivery. Except for the intranasal delivery, the others are very invasive and not so prone to clinical translation. Nonetheless, they are effective and thus commonly found in pre - clinical studies. Even so, the systemic administration route, such as i.v., continues to be the most used, despite the long pathway that the therapeutic/diagnosis molecules have to travel before reaching the CNS. Moreover, for systemic administrations there is a critical need to assure the protection and effective transport of the administered therapeutic agent (overcoming opsonization, immune recognition, and/or quick clearance). Finally, when a selected molecule reaches the nervous tissues, different cells are prone to uptake the delivered therapeutic. The ability to direct the therapy/diagnostic agent to a specific cell 
type has obvious advantages and appropriate strategies are being pursued where targeting moieties are used.

For the purpose of efficiently delivering a therapeutic and/or a diagnosis molecule to the CNS, engineered nanoparticles currently constitute one of the most powerful tools to cover some of the previously described requisites and to overcome cellular and extracellular barriers to delivery. An ideal nanocarrier for CNS therapeutic/diagnosis approaches should encompass a number of features, namely biocompatibility, the capacity to transport and protect its cargoes from degradation and/or rapid clearance (e.g., if systemically administered), the potential to reach the CNS, and specifically to target and deliver its cargo to the cell population of interest. Finally, biodegradability must also be equated, particularly in the context of regenerative therapies. Among the different delivery systems being explored-liposomes,13 polymeric micelles,14 linear polymers,15 quantum dots,16 iron oxide nanoparticles,17 and carbon nanotubes18-dendrimers/dendritic structures (Figure 2) are an emerging and particularly attractive class of nanocarriers for CNS drug delivery and diagnosis.19 


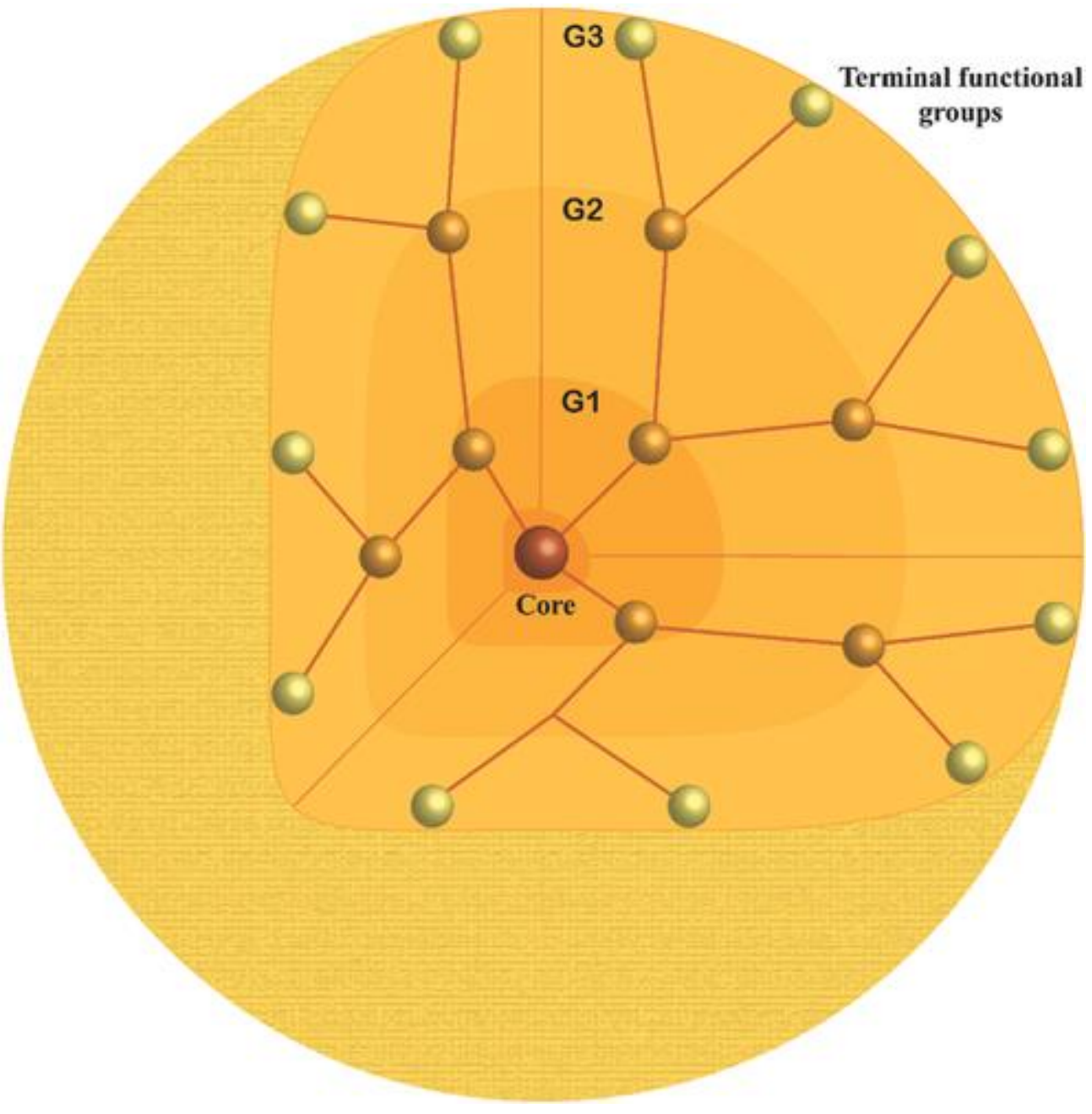

Figure 2. Schematic representation of a dendrimer structure with three generations (G).

In this review, we identify the currently existing dendritic systems, discussing their strengths and caveats in the context of attaining efficient therapeutic strategies for the treatment of neurological disorders.

\section{Dendrimers}

Dendrimers emerged from the "cascade molecules", a new class of highly branched molecules initially reported by Vögtle et al. at the end of 1970.20 Then, Denkewalter, Tomalia, Newkome, Frechet, and coworkers further enlarged the complexity of these systems, giving rise to bigger structures, then renamed them as "dendrimers".21 The word dendrimer comes from the Greek dendron ("tree" or "branch") and meros ("part"), and refers to the characteristic organization of their 
branched building units. Dendrimers consist of a) a bi - or multi - functional central core, b) building units covalently attached to the central core and organized in layers called "generations" (G), and c) a large number of end functional groups on their periphery (Figure 2).

The most researched dendrimers as vectors for CNS applications are the poly(amido amine) (PAMAM) dendrimers, 22 but others like poly(propylene imine) (PPI), [10, 22, 23] poly(L - lysine) based (PLL), [22, 24] carbosilane, 25 poly(ether) - copoly(ester) (PEPE), 26 phosphorus, 27 poly(ether imine) (PETIM), 28 and gallic acid-triethylene glycol (GATG) dendrimers 29 have also been explored (Figure 3). These and other dendrimers present very appealing features to mediate the delivery of drugs and bioactives to the CNS due to their unique structural properties: a globular, well - defined and very branched structure, as well as a low polydispersity, adaptable solubility, low viscosity, and controllable nanosize that allows for tight control and tuning of the size of the resulting dendritic nanoparticles (important when defining administration routes and/or the capacity to overcome certain biological barriers). Moreover, the abundance of peripheral functional groups allows the specific and controllable tethering of a great variety of bioactive ligands (Figure 4a), imitating the multivalency existing in several biological systems. In fact, this multivalency is the greater virtue of dendrimers. 

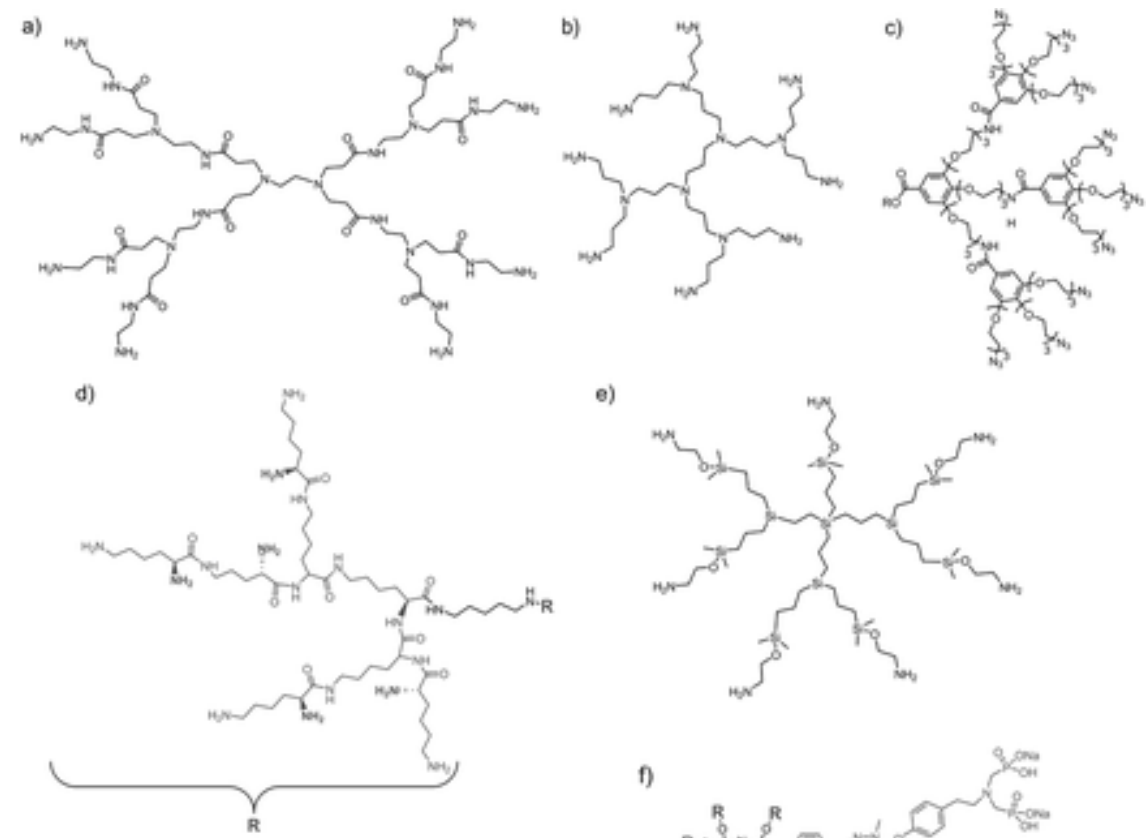

e)

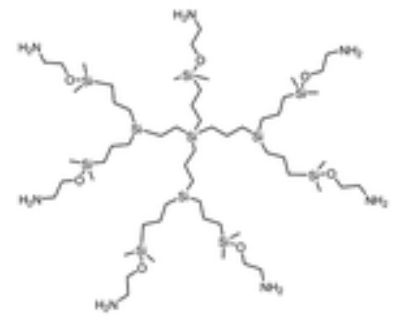

)
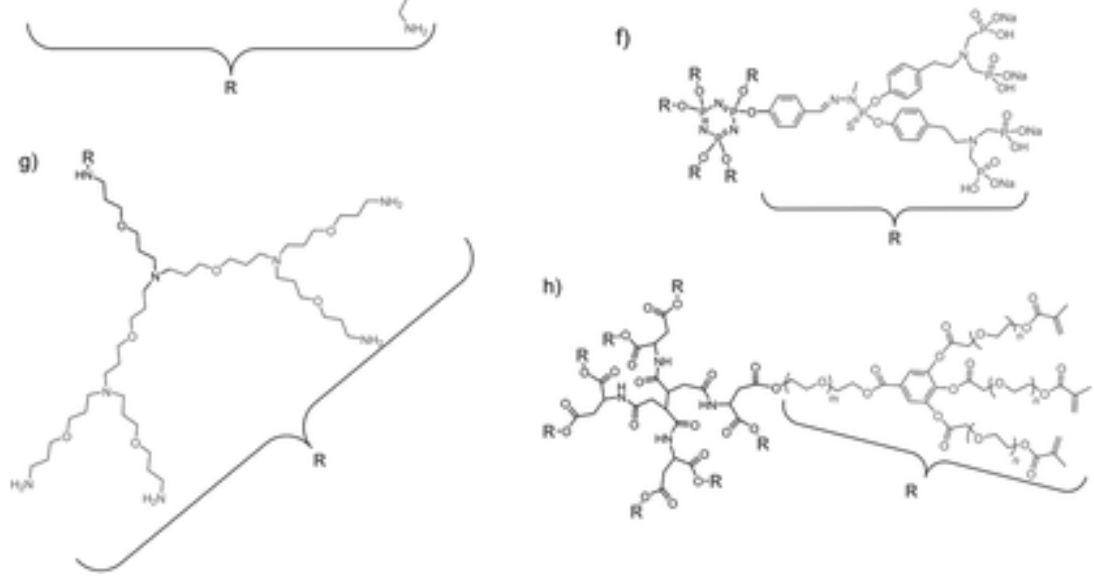

Figure 3. Partial structure of some of the currently used dendrimers in CNS applications: a) PAMAM; b) PPI; c) GATG; d) PLL; e) carbosilane; f) phosphorous; g) PETIM; and h) PEPE dendrimers.

Rua Alfredo Allen, 208 4200-135 Porto 


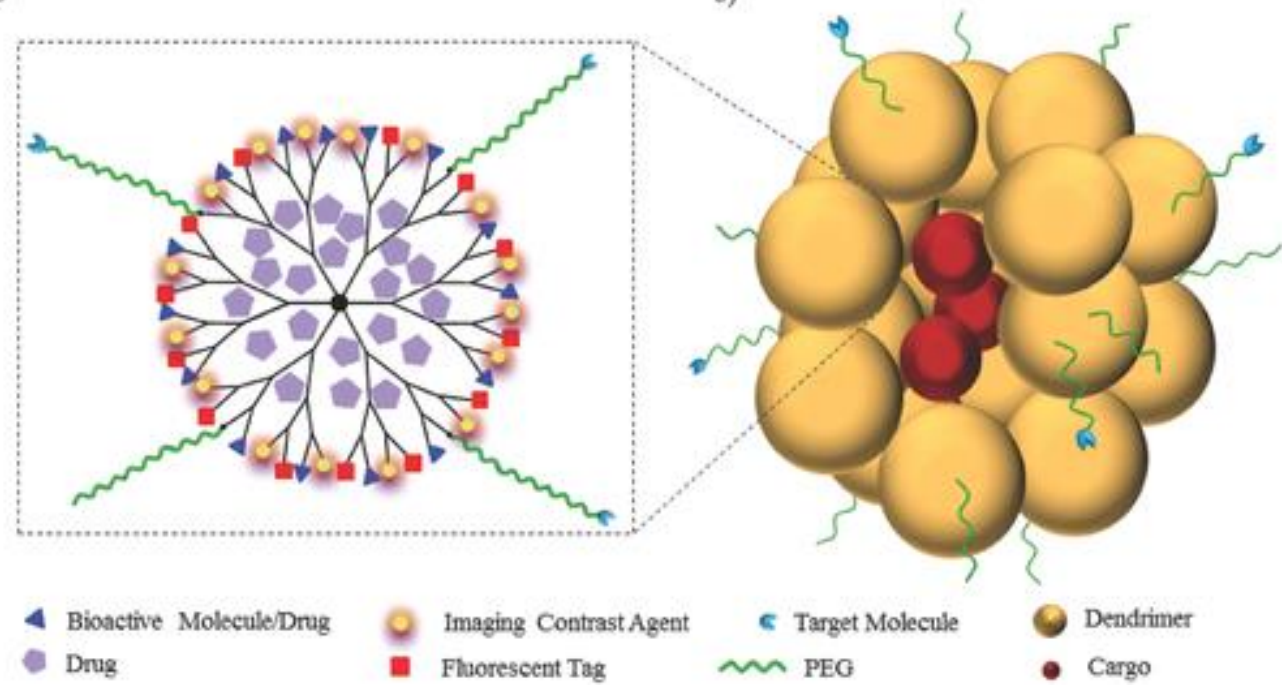

Figure 4. a) Dendrimer multifunctionalization and "dendritic box". b) Dendritic nanoparticle (cargo = drug, nucleic acid, protein, peptide, among others).

The enhanced effect that stems from the presentation of several and/or different bioactive molecules simultaneously at the same place causes an increase in the drug/ligand loading capacity that can contribute to the maintenance of drug levels in a therapeutically desirable range or an increase in the sensitivity and specificity of diagnostic systems. This high density of end functional groups also offers the possibility to link target molecules that can improve the delivery efficiency while decreasing side effects. Additionally, dendrimers can also cargo a molecule of interest by forming nanosized structures stabilized by non - covalent interactions (Figure 4). From a biological point of view, dendrimers can be applied through a diversity of routes of administration.30 Furthermore, dendrimers present reduced macrophage uptake (particularly for lower generations/sizes), facile biological barrier crossing, and rapid cellular entry,31 all of which are tunable by changing the concentration, generation/molecular mass/size, and/or surface groups/charge of the dendrimers.

All these properties make dendrimers very versatile and appealing nanocarriers, particularly presenting special advantages for transporting drugs across the BBB when in comparison with other nanomaterials.

Dendrimers are synthesized through an iterative synthetic methodology that consists of a series of repetitive growth and activation steps. The two conventional approaches to synthesize dendrimers are the divergent and the convergent methods (Figure 5). 
a) Divergent Strategy

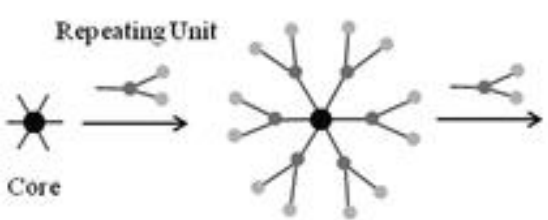

G1 Dendrimer

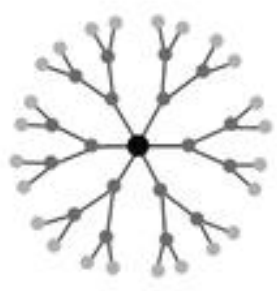

G2 Dendrime

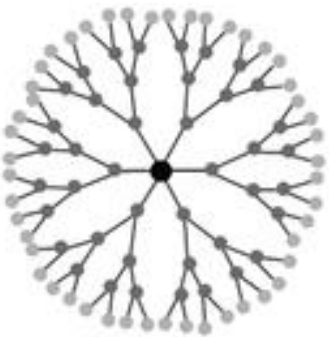

G3 Dendrimer

b) Convergent Strategy

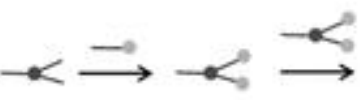

G1 Dendron

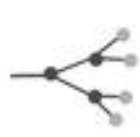

G2 Dendron

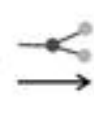

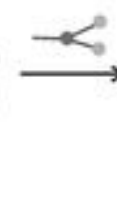

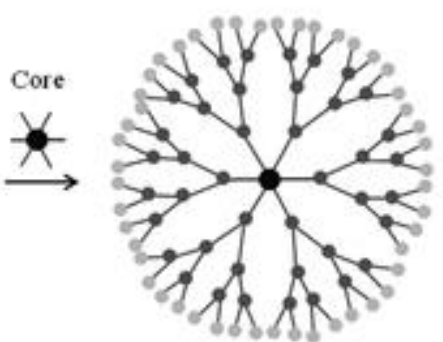

G3 Dendrimer

Figure 5. Classic strategies for the synthesis of dendrimers.

The divergent synthesis (Figure 5a), also known as the "starburst" method or the "inside - out" approach, was introduced by Vögtlezo and further developed by Tomalia[21] and Newkome.[21] It involves the growth of the dendrimers layer by layer from a multifunctional core site towards the periphery.32 The multifunctional core reacts with monomeric molecules or building units that contain one reactive and at least two inactive or protected branched sites to give the first dendritic layer or first generation dendrimer. Then, the surface/edge of the new molecule is activated/deprotected for subsequent reactions with more building units for expanding the dendrimers. The number of times this stepwise process is repeated will define the generation $(G)$ number and, therefore, the dendrimer size. And it can be repeated several times until steric hindrances impede the reaction of all peripheral groups with more building units due to surface crowding for high generation dendrimers. Even so, this strategy has allowed for obtaining high generations in particular cases, namely, G9 for poly(phenylene) dendrimers,33 G10 for PAMAM,34 G12 for phosphorus dendrimers,35 and even $\mathrm{G}_{13}$ for triazine dendrimers.36 The convergent approach (Figure 5b), established by Fréchet et al. in 1990,[21] can be considered as the reverse of the divergent approach. This strategy involves the synthesis of perfect branched and individual dendrons (dendrimer wedges), which finally are attached to a multifunctional core after activation/deprotection of their focal point, in an "inward" process.[32]

The divergent strategy presents the disadvantage of building dendrimers with structural defects due to the higher number of reactions performed at the same time and therefore usually requires purification after each step. 37 The probability of obtaining side - products increases with generation, which further results in lower overall yields. Contrarily, in the convergent approach, since only a confined number of groups is active per step, the probability of structural defects is lower.37 However, a major disadvantage is its low ability to produce dendrimers of higher generations due to 
the steric hindrance between increased dendrons in the last step. Although an adequate choice of the multivalency and size of the core could reduce steric hindrance effects.37

To conquer these drawbacks and the often tedious and time - consuming processes of these classical strategies, new faster and simpler synthetic approaches have been reported, including "click chemistry",38 "Lego" chemistry,39 and accelerated,40 orthogonal40, 41 and chemo - selective growth strategies, 40 which render higher branching or number of terminal groups and reaction efficiency while reducing the number of reaction and purification steps. Methods that do not require any purification after each step because they only produce innocuous byproducts (e.g., water and sodium chloride), have been also reported.42 These improvements diminish the use of starting materials, chemicals, and side products. Consequently, these improved syntheses are less time - and cost - consuming, as well as more environmentally friendly.

In general, all these strategies yield products with well - defined structures and low polydisperse sizes, which are quite engaging not only from a synthesis reproducibility point of view but also for reducing experimental variability in the different applications. In fact, this optimization and increased easy accessibility to more and more sophisticated dendrimers has led to the commercialization of different families of dendrimers while others are on the brink of this. As a consequence, the number of applications has exponentially increased, including biomedical ones. In fact, some diagnosis and/or in vitro dendrimer - based technologies are already on the market. Namely, the Stratus ${ }^{\circledR}$ CS Instrument (Siemens Healthcare) that takes advantage of a PAMAM dendrimer - based biosensor carrying a monoclonal sheep antibody for fast and accurate cardiac detention of patients with suspected myocardial ischemia and two PAMAM - based transfection agents for in vitro assays (Superfect ${ }^{\circledR}$ (G6) and PriofectTM) marketed by Qiagen and Starpharma, respectively. A DNA chip (DendrisChipTM) based on phosphorous dendrimers has also been proposed by the biotech company Dendris for the detections of a broad range of viruses and pathogens with high sensitivity and specificity. Other dendrimers have already reached human clinical trial; such is the case for Gadomer ${ }^{\circledR}$ - 17 (also known as SH L 643 A; Schering AG), which is a PLL dendrimer holding 24 gadolinium (III) - DOTA chelate groups at its surface (commercial name Dotarem ${ }^{\circledR} ;$ DOTA $1,4,7,10$ - tetraazacyclododecane - 1,4,7,10 - tetraacetic acid). This was the first dendrimer - based product entering into clinical evaluation as a blood pool contrast agent for magnetic resonance angiography. 43 However, despite the promising early clinical results, Gadomer ${ }^{\circledR}-17$ clinical testing was not pursued further, although it is currently being commercialized as a pre - clinical research contrast agent. In cancer therapy research, DEP ${ }^{\mathrm{TM}}$ docetaxel emerged as a dendrimer - enhanced version of docetaxel (Taxotere ${ }^{\circledR}$ ) for solid tumor treatment by systemic administration. In pre clinical studies, DEP ${ }^{\circledR}$ docetaxel showed greater anti - cancer effects as compared to Taxotere ${ }^{\circledR}$, and thus it is now in phase I clinical trial in patients with advanced solid tumors.44 Finally, VivaGel ${ }^{\circledR}$ from Starpharma is a $\mathrm{G}_{4}$ - PLL - based dendrimer formulated as a water - based mucoadhesive gel to be delivered vaginally. This gel was approved by the Australian Therapeutic Goods Administration in 2014 and gained European regulatory approval for topical treatment and rapid relief of bacterial vaginosis in 2015. Phase III clinical trials are ongoing to evaluate its potential in prevention of recurrent bacterial vaginosis. 45 Vivage ${ }^{\circledR}$ is also being investigated as vaginal microbicide to prevent the transmission of genital herpes (HSV - 2), human immunodeficiency virus (HIV) infections, and other sexually transmitted infections including human papillomavirus (HPV), the causative agent of cervical cancer.46 It is also being used as a condom coating due to its antiviral and antibacterial properties (only available for the Australian market at present). 47 


\section{Dendrimers as CNS Delivery, Imaging and Diagnosis Systems}

Due to the easy tuning regarding composition, structure, and size, dendrimers are versatile systems to serve as vectors for numerous biomedical applications, including brain delivery and diagnosis. They are being explored as promising carriers of chemical drugs, therapeutic nucleic acids (NAs), proteins and peptides, as well as macromolecular contrast agents and biosensor platforms for CNS therapies, imaging, and diagnosis (Figure 4). The strategies of preparation of the bioactive dendrimer systems are briefly discussed in the following paragraphs, according to the type of bioactive that is being linked/transported.

\subsection{Chemical Drug Delivery}

Dendrimers present optimal guest-host properties for accommodation of different chemical drugs. These can be contained inside dendrimers ("dendritic box" model, Figure 4a) 48 through non covalent interactions: electrostatic, 49 hydrogen bonding, 26 and, mostly, hydrophobic interactions, as in the case of some anticarcinogenic drugs used for the treatment of brain tumors. $[23,26,50]$ Alternatively, drug conjugation to the dendrimer can be pursued. The large density of different functional surface groups on dendrimers, namely hydroxyl - , thiol - , amine - , carboxylic acid - , azide - , allyl groups, and so on, provide a unique chance for ionic coordination 51 or covalent attachment of drugs, which can be directly tied to the dendrimers through different linkages.[22, 52] The conjugation approach is very appealing because it further allows the engineering of drug delivery systems susceptible to stimuli by linking the drug through cleavable chemical ( $\mathrm{pH}$ or redox sensitive) or enzymatic bonds. 53 Therefore, a better control of the kinetics of drug release can be achieved.[22, $52,54]$ The major downside of this approach is the increased complexity in the chemical design of the conjugates, as well as the direct exposure of the bioactives to the tissue environment upon administration. On the contrary, simply entrapped drugs into the dendritic box stay more protected. Nevertheless, a lower number of bioactives can be encapsulated, the guest molecules can prematurely diffuse out of the dendrimer, and/or their release kinetics cannot be strictly controlled. 54 Since both approaches present their own pros and cons, 55 some researchers have also evaluated the combination of both approaches simultaneously. 54

\subsection{Nucleic Acid Delivery}

Cationic dendrimers have the ability to complex and protect NAs in compact structures called dendriplexes through electrostatic interactions. 56 Because of this, dendrimers are also appealing non - viral vectors that can help to surpass the different extra - and intracellular barriers encountered in order to efficiently deliver exogenous therapeutic NAs, such as plasmids[10, 22] and siRNA, $[22,25]$ into CNS cells. Moreover, the possibility of multifunctionalization in dendrimers also allows using them to act as co - delivery systems of different bioactive simultaneously. For instance, the delivery of NAs and chemical drugs has been explored, as will be detailed in section 6.[24]

\subsection{Protein and Peptide Delivery}

Although very scarcely explored yet, dendrimers have also been tested as protein 57 and peptide 58 carriers. Concerning the delivery of proteins, the direct conjugation of the protein to the dendrimer is not suitable because of their similar molecular weights and sizes, so complexation and/or encapsulation are more adequate strategies. In the reported dendritic systems for protein or peptide 
delivery, the main interactions established between the carrier and cargoes are electrostatic. Nevertheless, especially in the case of proteins, hydrophobicity was also found to play an important role in this process.59 To the best of our knowledge, for now, there is no report exploring dendrimers as delivery vehicles of protein or peptides in the context of CNS.

\subsection{Macromolecular Contrast Agents}

For brain medical diagnosis, an interesting case of dendrimer conjugation is the covalent attachment of diagnosis agents for the preparation of dendritic macromolecular contrast agents for $X$ - ray imaging, such as computed tomography (CT) and magnetic resonance imaging (MRI).19 The aim is to obtain large molecular weight contrast agents to improve the image contrast, stability, water solubility, biocompatibility, and pharmacokinetics, while minimizing toxicity and required dose. The most widely explored dendritic contrast agents for MRI are based on small paramagnetic gadolinium(III) chelates (Gd(III) - DTPA (DTPA = diethylenetriaminepentaacetic acid, Magnevist ${ }^{\circledR}$ ) and $\mathrm{Gd}(\mathrm{III})$ - DOTA (Dotarem $\left.{ }^{\circledR}\right)$ ) conjugated to dendrimers.6o Additionally, organometallic complexes of dendrimers and dendritic nanoparticles with heavy isotopes of iodine have also been investigated as $X$ - ray contrast agents. 61 Nevertheless, to the best of our knowledge, dendrimers have never been applied as $X$ - ray macromolecular contrast agents in the brain imaging context. Therefore, this would be an interesting application to be explored, since multivalent dendrimers represent one of the most appealing systems to take manifold contrast agent moieties, 6o, 62 as well as to concomitantly join target molecules, offering a sole chance to enhance site - specific image contrast. 63

\subsection{Biosensors}

The previously discussed guest-host properties of dendrimers also allow accommodating molecular probes, by encapsulation or covalent conjugation. This, together with the possibility of fine tuning and tighter control of their chemistry composition and architecture (i.e., core, backbone, and surface groups), make dendrimers very attractive platforms for the design and development of high sensitivity sensors.64 Moreover, dendrimers can help to surpass the problems related to the response variability due to the limited sensor molecule loading efficiency, limited accessibility of the probes, poor control over uniform spacing among the probes, and a loss of functionality due to irregular orientation of the probes. In fact, researchers have demonstrated that dendritic macromolecules show improved sensitivity and accessibility of the probe for the target analyte and high stability, minimize non - specific binding, and provide a low variability in their response. Therefore, the development of dendrimer - based sensors is an advantageous way to obtain higher sensor performances and reduce the whole preparation cost. Dendrimers could, therefore, convert into very interesting tools for functional CNS imaging and diagnosis. 65

\section{Tailoring Dendrimer - Based Delivery Systems for CNS Applications: (Bio)functionalization, Targeting and Labeling}

The tunable chemistry of dendrimers permits a precise "chemical makeup" that allows the design, in principle, of an almost unlimited number of molecules. This, together with the possibility of an accurate chemical multi - decoration with several (bioactive) ligands and/or target molecules, permits dendrimers to act as "smart" nanosystems for the efficient and site - specific delivery of several agents to the CNS.

\section{西}




\section{1 (Bio)functionalization}

Depending on the desired application, target cells/tissue, type of administration, and characteristics of the bioactive to be linked and/or carried, dendrimers can be properly (bio)functionalized using different strategies.

To interfere in $A \beta$ - amyloid fibril formation, which might represent a new method to address the key pathology in $A D$, amine - terminated $G_{4}$ and $G_{5}$ PPI dendrimers were decorated with maltose and maltotriose by reductive amination in a one - pot approach.[23] With the same objective, morpholine was introduced on the surface of $\mathrm{G}_{3}$ GATG by means of $\mathrm{Cu}(\mathrm{I})$ - catalyzed azide - alkyne cycloaddition (CUAAC, click chemistry). 29

In the context of drug release, previously mentioned strategies aimed to afford a control of kinetics of drug liberation have also been tested for brain delivery. For example, the anti - carcinogenic doxorubicin (Dox) has been attached to $\mathrm{G}_{4}$ PAMAM dendrimers via an acid - sensitive cis - aconityl linkage[22] and to $\mathrm{G}_{3}$ dendrigraft poly( $\mathrm{L}$ - lysine) (DGL) through $\mathrm{pH}$ - trigged hydrazone bond, [24] what favors a fast Dox release in the acidic tumor environments. However, these acid - labile linkages are not an adequate approach for the treatment of CNS diseases, like neurodegenerative disorders, in which the $\mathrm{pH}$ persists neutral. Ester linkages are the preferred option in these cases and/or when a more prolonged drug release under acid and neutral $\mathrm{pH}$ is desired. Moreover, one can also play with the nature of the used linker/spacer to attach the drug to the dendrimer to further tune the hydrolysis rate of the ester group, and thus to maintain the drug release during the desired period of time. lezzi et al. linked fluocinolone acetonide (a drug for attenuation of neuroinflammation in the retina) to hydroxyl - terminated $\mathrm{G}_{4}$ PAMAM (G4 PAMAM - $\mathrm{OH}$ ) via an ester bond using a glutaric spacer, observing a sustained drug release for a period over 90 days.[22] On the contrary, Sk and co workers used the ester strategy to link two anticancer drugs (estramustrine and podophyllotoxin) to the same type of dendrimer (G4 PAMAM - OH) through a succinic acid linker, obtaining a sustained release during a significantly shorter time period (6 days).[52]

In a similar manner, disulfide bonds were also explored as degradable (reductible) linkages through the use of different linkers/spacers. For instance, a small linker, namely succinimidyl 3 - (2 pyridyldithio)propionate (SPDP), has been commonly explored to hang different brain drugs and/or bioactives to dendrimers via disulfide bonds. Such is the case of $\mathrm{N}$ - acetyl cysteine (NAC)[22] (attenuator of neuroinflammation) and thiol - functionalizated valproic acid[22] (excitotoxicity attenuator), which were attached to $\mathrm{G}_{4}$ PAMAM dendrimers using this dithio - spacer. On the other hand, Kaneshiro et al. used the dithio - spacer ( 4 - succinimidyloxycarbonyl - $\alpha$ - methyl - $\alpha$ - [2 pyridyldithio]tolvene) (SMPT) to hang Dox to G3 PLL dendrimers via the disulfide linkages strategy as well, where PLL was thiolated with 3 - mercaptopropanoic acid) a priori.[24] More stable amide bonds were used to link the anti - carcinogenic curcumin and methotrexate to $G_{3}$ and $G_{5}$ PAMAM dendrimers, respectively, via the frequently used carbodiimide chemistry.[22,66] Also, boron - 10 enriched methylisocyanato polyhedral borane anion was connected to $G_{4}$ and $G_{5}$ PAMAM via stable carbamide linkers in order to obtain the corresponding boronated dendrimers for neutron capture therapy (NCT) of brain tumors. $[52,67]$

\subsection{Overcoming the BBB}


Dendrimers can gain access to the CNS microenvironment by either passive or active targeting. The passive targeting can occur either as a result of the enhanced permeability and retention (EPR) effect or as a consequence of the selected administration route. The EPR effect relates to the propensity of molecules to preferentially accumulate at sites of increased vascular permeability, such as sites of inflammation, infection, or tumors. However, as previously mentioned, after certain insults (like in the case of stroke or a traumatic $\mathrm{SCl}$ ) the BBB at the injury site is compromised for a limited period of time. Therefore, due to the EPR effect, systemically administered dendrimers have the potential to overcome the BBB and passively and effectively target the diseased brain. Nevertheless, the EPR dependent molecule accumulation is slow, and thus only a small portion of the circulating molecules actually reaches tumors or sites of inflammation/infection, while the majority tends to accumulate in the liver and kidneys (filtering organs) or even in the lungs and heart in the case of large entities, like particulate systems. As previously mentioned, an additional strategy to surpass the BBB is to select an appropriate route of administration (Figure 1) that, per se, avoids this barrier. However, the invasiveness of some of these routes can be an obstacle.

Therefore, to overcome these drawbacks, dendrimers can be actively functionalized on their surface with targeting ligands that selectively guide their binding to receptors or specific molecules overexpressed at the target cell, tissue, or organ.68 In this regard, several BBB receptor - mediated transport mechanisms have been exploited as the route for CNS access. The brain capillary endothelial cells, as well as many malignant tumor cells, overexpress transferrin receptors (TfR), which renders the transferrin (Tf) family as useful targeting ligands to facilitate the BBB transport or gain access to brain tumors. The Tf family is a group of glycoproteins with the ability to bind and transport non - heme iron, although some homologues have evolved different functions.69 Huang et al. targeted a poly(ethylene glycol) (PEG) - modified G5 PAMAM (G5 PEG - PAMAM) dendrimer with Tf that was able to transport NA to the brain following an i.v. administration.70 In another study from Somani et al., a Tf - bearing $\mathrm{G}_{3}$ diaminobutyric PPI dendrimer (DAB) was able to increase the dendrimer cellular uptake and transgene expression by cancer cells overexpressing TfRs, as compared to non - functionalized dendrimers, both in vitro and in vivo after an i.v. injection.[10] Using the same G 5 PEG - PAMAM, Huang et al. also explored the use of lactoferrin (Lf), a single chain iron - binding glycoprotein, as a brain targeting ligand. These authors demonstrated the improved ability of Lf - functionalized/targeted complexes to cross an in vitro BBB model, as well as their in vivo brain targeting ability via an i.v. administration, in comparison with their non functionalized or Tf - conjugated counterparts.71 The dual brain targeting was also investigated by the combined use of Tf and wheat germ agglutinin (WGA) or tamoxifen (TAM). WGA is a lectin with a strong affinity to the brain capillary endothelial cells and tumor cells, but with a low affinity for normal tissues. Likewise, TAM is an estrogen receptor modulator with a suggested improved BBB transport. Both the Tf/WGA and Tf/TAM modified PAMAM dendrimers showed a synergistic BBB targeting effect and, therefore, a higher BBB transportation and payload release to the avascular C6 glioma spheroids in vitro. $[22,50]$ Despite the success of all the examples described above, the use of Lf and Tf as targeting ligand can be compromised by the competition with their endogenous equivalents. In this regard, other recent studies have demonstrated the use of HAIYPRH (T7) peptide to specifically target the TfR with a similar affinity as Tf.72 Moreover, T7 peptide and Tf bind to distinct sites on the TfR and thus, they do not compete for the receptor binding. Using a PEGylated G3 DGL dendrimer modified with the T7 peptide, the Jiang group has demonstrated the brain targeted delivery of anti - tumoral therapeutics in an orthotopic human glioma model, providing new therapeutic opportunities to brain tumor treatment.[24]

INSTITUTO DE INVESTİGAÇÃO E INOVAÇÃO EM SAUDE UNIVERSIDADE DO PORTO

Rua Alfredo Allen, 208 4200-135 Porto Portugal +351 220408800 
Apart from the Tf family of ligands, additional brain targeting molecules have been probed. Angiopep - 2 is a peptide that binds to the low - density lipoprotein receptor - related protein 1 $\left(\mathrm{LRP}_{1}\right)$ that is ubiquitously expressed in the CNS and takes advantage of a receptor - mediated transcytosis mechanism to cross the BBB. This peptide possesses a higher BBB penetration capability than other proteins, such as Tf and Lf. Angiopep - 2 has been used to mediate the target delivery of PAMAM and DGL dendritic structures in CNS disorders, such as brain cancer or Parkinson disease (PD). $[24,73]$ In another study, a 29 - amino - acid peptide derived from the rabies virus glycoprotein (RGV29) was shown to be an effective brain targeting ligand as well. In a similar manner to its parent protein, RVG29 peptide binds specifically to the nicotinic acetylcholine receptor ( $n A c h R$ ) present on neuronal and brain capillary endothelial cells, and when linked to the surface of PAMAM it was able to mediate in vivo the efficient dendriplex accumulation and reporter gene expression in the brain upon i.v. administration.74

From the point of view of the chemical strategies explored to attach the discussed targeting moieties to dendrimers, less labile bonds (like carbamates, amides, imines, and thioethers, among others) than those used in the majority of the cases described for the biofunctionalization/drug conjugation have been explored. In fact, the most commonly used strategy to tether the above - mentioned brain targeting ligands to dendrimers was through the widely known bifunctional PEG presenting $\mathrm{N}$ hydroxysuccinimide (NHS) and maleimide (MAL) as terminal groups (NHS - PEG - MAL). This approach supposes the establishment of an amide bond between the dendrimer and PEG dendrimer, and of a thiosuccinimide linkage between the PEG and the protein/peptide. $[22,24,70,71,73-75]$ The exploration of PEG as a linker has several functions: on one hand, it forces the exposure of the targeting moiety, and on the other hand, it improves biocompatibility, provides longer circulation times, and reduces immunogenicity while increasing water - solubility and enhancing the structural stability of the targeted systems. Although this is the most resourced strategy to tether targeting moieties to dendrimers, there are also few groups that have explored alternative approaches. For instance, in the aforementioned work from Somani et al., Tf was attached to $G_{3}$ DAB via a dimethyl suberimidate (DMSI) cross - linking agent.[10] Also, it is worth mentioning the particular case reported by Li et al. where the dendrimer was used as a "dendritic box" to entrap TAM, used here as a targeting moiety.[22]

\subsection{Tumor Cell Targeting at the CNS Level}

In tumors, the EPR effect appears and the BBB permeability increases mainly as a consequence of cancer angiogenesis and extensive production of vascular mediators that facilitate extravasation. The newly formed vessels are usually abnormal and present large fenestrations. Consequently, in such settings, dendritic structures or dendritic - based nanoparticles with suitable size, less than 100 $\mathrm{nm}, 76$ can enter the brain tissue via endothelial gaps. Once within brain tissue, dendrimers for anti tumoral therapy should recognize their target-brain tumor cells. For this, several groups have explored a number of brain - tumor - targeting ligands that specifically bind to different proteins on the surface of brain tumor cells. The most studied are the epidermal growth factor receptors (EGFR), integrins, and extracellular matrix (ECM) modulators.

The EGFR and its mutant isoform EGFRvIll are transmembrane receptors expressed at high levels in various types of tumors, including brain tumor cells. The cetuximab ( 225 ) antibody, specific for both wild - type EGFR and EGFRvIII, has been probed for glioma targeting by Barth and colleagues. They reported the efficacy of $\mathrm{C}_{225}$ - PAMAM dendrimers carrying around 1100 boron atoms (B1100), 
i.c. - administered by convection - enhanced delivery (CED), to significantly increase B1100 accumulation in brain tumor tissues in comparison to healthy brain tissues, assuring the success of boron neutron capture therapy.[67] Moreover, they also demonstrated that direct i.c. administration of $\mathrm{C} 225$ - conjugated PAMAM - methotrexate dendrimers by CED to glioma - bearing rats resulted in a specific molecular targeting of the tumor.66 Other EGFR/EGFRvIll targeting moieties also investigated include monoclonal antibody specific to EGFRvIII, such as the EGF[52] and L8A4.[67] In these cases, the approach followed to decorate $G_{4}$ and $G_{5}$ PAMAM dendrimers with the brain targeted antibodies, consisting of the aforementioned SPDP linker together with a $\mathrm{N}$ - (K maleimidoundecanoic acid)hydrazide (KMUH).[52, 66, 67] PAMAM dendrimers were functionalizated with thiols through the attack of its primary amines to the succinimidyl group of the SPDP, while maleimides were introduced in the antibodies via the KMUH linker. Then, targeted dendrimers were obtained by reaction between both groups (thiols from PAMAM and maleimides from antibodies).

Integrin expression, particularly integrin $\alpha v \beta_{3}$, is prominent in glioma tumors but not on normal brain cells. The cyclic arginine-glycine-aspartic acid (RGD) peptide and its analogs have been widely investigated as ligands for integrin and, therefore, for glioma targeting strategies. Previous studies showed that i.v. - administered RGD - modified dendrimers are capable of enhancing tumor penetration and accumulation, resulting in a general anti - tumor effect of the chemotherapeutic drug Dox.[22, 24]

Chlorotoxin (CTX) is a 36 amino - acid peptide purified from the Leiurus quinquestriatus scorpion venom that binds with high affinity to the matrix metalloproteinase - 2 (MMP - 2) preferentially up - regulated in tumor cells of the neuro - ectodermal origin. Huang et al. exploited the PAMAM CTX conjugates to carry a plasmid encoding for tumor - necrosis - factor - related apoptosis inducing ligand (TRAIL) into intracerebral glioma - bearing mice. Upon intratumoral administration, these conjugates were able to increase their accumulation in brain tumor tissues and provoke a more widely extended apoptosis as compared to the group of animals treated with the commercially available drug temozolomide (chemotherapy drug).[75]

Other studies exploited the potential of using D - glucosamine as both BBB permeability enhancer and tumor targeting agent, 26 as well as the use of cationic arginine residues, 77 thiamine,[23] polysorbate 80 surfactant, [23] and the fibrin - binding peptide CREKA,[22] as brain tumor targeting molecules.

With regards to the chemical approach for carrying out the targeting in these last few examples, while RGD peptide, $[22,24]$ CREKA[22] and CTX[63] were linked via the well - known and previously described NHS - PEG - MAL strategy to the dendrimers, glucosamine and some hydroxylated target molecules, such as polysorbate 80 and thiamine, were conjugated to $\mathrm{G}_{2}$ PEPE and $\mathrm{G}_{5}$ PPI dendrimers by using disuccinimidyl carbonate 26 and carbonyl diimidazol (CDI), [23] respectively.

\subsection{In Vitro and In Vivo Tracking}

In order to follow the biodistribution of the dendritic delivery systems in vitro and in vivo, these can also be tagged with fluorescent dyes or radioactive atoms. Among the fluorescent dyes, the most widely used are fluorescein,[22] Cyanine 5 (Cy5), [22] boron - dipyrromethene (BODIPY), [70, 73, 75] and rhodamine 26 derivatives, although others labels like Alexa Fluor ${ }^{\circledR} 647$ or IR783 have also been 
used.4, 78 Nowadays, all these fluorescent dyes are sold with suitable functional groups to obtain an easy and stable attachment to the different terminal dendritic groups. In the majority of the cases summarized in this review, the most used ways to tag the dendrimers were based on carbodiidime, NHS, and isothiocyanate chemistry.

To track the in vivo distribution of the dendritic systems, these can also be radiolabeled. Examples include the $G_{5}$ PAMAM70, 74 and G $_{3}$ DGL[22] dendrimers, which were radiolabeled with 125 l via the commonly used 1251 - Labeled Bolton - Hunter reagent.

\section{Applications of Dendrimers in the CNS}

The incidence of CNS diseases, especially those related to aging, has sharply increased in recent years due to the increment in life expectancy. This has put great pressure in the development of CNS therapeutics and its effective delivery.

To support the use of dendrimers as promising delivery vectors to the CNS it is important that their mechanism of action is understood. To investigate the uptake of dendrimers specifically by the key cellular unit of the nervous system - the neuron - the process and kinetics of internalization of these macromolecules has been studied. Different endocytic mechanisms for PAMAM dendrimers have been observed in hippocampal neuronal cell cultures, including clathrin - and caveolae - mediated internalization.79 The process appears to be dependent on the chemical surface modification of the PAMAM, as described by Hugh and colleagues, where unmodified (positively charged) and folic acid decorated dendrimers were internalized by both clathrin and caveolae endocytosis, while neutral and anionic dendrimers were not internalized. This lack of neuronal association observed for the latter has been explained by differences in the dendrimers' net charge. Functionalization of $50 \%$ of the amine surface groups with PEG led to neutral dendrimers, while the modification of $30 \%$ of amine surface groups with acrylate anionic groups rendered negatively charged dendrimers. In this context, another study has addressed the uptake of nanoparticles composed of carboxymethylchitosan/PAMAM dendrimers (CMCht/PAMAM) in CNS neuronal and mixed glial cell cultures. The results showed that, similarly to what was observed for all three glial cell types (oligodendrocytes, astrocytes, and microglia), hippocampal neurons were able to internalize dendrimers periodically given to the cultures for 1 week. 80 The distinct rates of internalization were attributed to differences in proliferation, endocytic capacity, and different functions of each cell type; for example, the highest internalization for microglia was attributed to its phagocytic function.

As previously commented, with the aim to increase the efficiency in crossing the BBB, dendrimers can be targeted with specific BBB ligands. This was illustrated in the case of PAMAM modified with the Angiopep - 2, a peptide recognized by the $L R P_{1}$, which is abundantly present in the $B B B$ endothelial cells.[73] This strategy resulted in an increased accumulation of the dendrimers in the mouse brain, 2 hours after i.v. administration, when compared to the unmodified PAMAM. However, the contribution of the PEGylation was not assessed in this study. Different brain structures were then analyzed, and while PAMAM was present at the cortex and caudate putamen, PAMAM Angiopep was additionally present at the hippocampus and substantia nigra.

When reaching the CNS after successfully crossing the BBB, the dendriplexes/nanoparticles must move through cells and tissues, i.e., these must diffuse through the parenchyma. A very interesting study using $\mathrm{G}_{4}$ PAMAM and 2 - hydroxydodecyl modified $\mathrm{G}_{4}$ PAMAM ( $\mathrm{C}_{12}$ - PAMAM) dendrimers 
showed that the $25 \%$ surface amine groups modification with this $\mathrm{C}_{12}$ - lipid induced in vitro toxicity and prevented parenchymal diffusion in vivo, while $\mathrm{G}_{4}$ PAMAM was most adequate for penetrating the brain parenchyma without causing toxicity or interfering with neural activity, as demonstrated by electrophysiological studies.4

In the following paragraphs, the dendrimer - based therapeutic and theranostics explored so far in the context of CNS are reviewed and discussed in detail.

\title{
6.1 Vascular Diseases
}

Treating neuronal damage after a cerebrovascular accident is a challenging issue and for this reason it is considered a major vascular disease. A cerebrovascular accident occurs due to an occlusion of a major artery (ischemic stroke) or rupture of a blood vessel (hemorrhagic stroke). In both cases, the therapeutic options available are reduced. Further challenges result from the limited window of opportunity to interfere with the pathological mechanism and the difficult access of therapeutics to the afflicted neurons.

A recognized experimental model for ischemic stroke is to transiently occlude the middle cerebral artery with a monofilament.81 This and other models 82 have allowed the study of neuroprotective therapies based on, for example, RNA interference (RNAi) strategies. An and colleagues reported the delivery, by a tail vein injection, of apoptosis signal - regulating kinase 1 (Ask1) shRNA plasmid using a G3 DGL dendrimer with the aim to interfere with the mitogen - activated protein kinase (MAPK) cascade signaling pathway after transient ischemia.83 To target the dendriplexes to the brain, DGL was decorated with dermorphin (an $\mathrm{m}$ - opiate receptor agonist), which significantly elevated the relative accumulation of shRNA plasmid in the brain as followed by in vivo bioimaging. Nanoparticles were detected in ventricle, hippocampus, cortical layer, substantia nigra, and corpus striatum. As a measure of neuroprotective effect, the cerebral infarct volume was analyzed, resulting in a decreased value that reflected the efficient decrease of Ask1 expression by RNAi. Other similar NA - based neuroprotective strategies in ischemia have been performed by means of arginine - modified PAMAM dendrimers (e - PAM - R) as vectors for the high mobility group box 1 (HMGB1) siRNA delivery after intranasal administration,[22] and also by the use of carbosilane dendrimers to deliver hypoxia - inducible factor ( $\mathrm{HIF}_{1}$ - alpha) siRNA after induced hypoxia in cultured cortical neurons as a proof of concept.[25] Moreover, a PAMAM - dexamethasone conjugate to deliver the heme oxygenase - $1(\mathrm{HO}-1)$ gene into the ischemic brain by stereotaxic injections was also reported.[22] In this study, dexamethasone was used to convey anti - inflammatory effects 84 and also to simultaneously aid gene delivery as it binds to glucocorticoid receptor complexes, increasing nuclear localization. 85 Overall, the outcome of the therapies was very positive, since the dendrimers showed a superior performance when compared with commercial transfection agents, as well as a therapeutic effect with a significant decrease in infarct volume, which opens new possibilities for gene therapy in stroke using dendrimers as delivery vectors.

Another example from Kannan and co - workers shows the use of a $\mathrm{G}_{4}$ PAMAM - $\mathrm{OH}$ to reach the injured brain after global ischemia induced by hypothermic circulatory arrest in a canine model.[22] Upon i.v. administration, biodistribution studies revealed the dendrimers' presence in brain regions vulnerable for glutamate excitotoxicity, such as the hippocampus, cerebellum, and cerebral cortex. It was observed that dendrimers were selectively taken up in the injured hippocampal dentate granule cell layer, in cerebellar Purkinje and granule neurons, and in microglia. This study associates

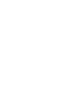


excitotoxicity with dendrimer neuronal uptake, which is relevant for reaching the injured neuron population and ultimately in novel nanomedicine - based therapies.

\subsection{Neurodegenerative Diseases}

Millions of people are affected worldwide by neurodegenerative diseases, being AD and PD the diseases with the higher incidence. The risk of developing a neurodegenerative condition increases dramatically with age. This is a commonly accepted reality for $A D$, which occurs due to the amyloid beta $(A \beta)$ accumulation in the brain, leading to dementia. The number of patients and relatives affected, directly or indirectly, is enormous and, therefore, the research efforts on AD are vast. In the field of dendrimer - based nanomedicine, AD fulfils a big piece of the research focus. For example, different studies have addressed the effect of distinct dendrimers on $A \beta$ formation envisaging a future application on AD therapy. By using cationic phosphorus dendrimers[27] or the GATG dendrimers decorated with terminal morpholine groups,29 the interaction with $A \beta$ was detected, and a closer inspection showed alterations in the aggregation pathway. Dendrimers influence on $A \beta$ aggregation and disruption of mature fibrils prompted a study in a neuroblastoma cell line where a G3 PLL dendrimer was able to protect cells from $A \beta$ toxicity and in vivo studies, using rats after unilateral intracerebroventricular injection, showed the presence of these dendrimers in different brain cell populations, like the hippocampal and cortical neurons.[24] This should have implications in $A D$ pathology because the widespread localization of the dendrimers should be able to reach the disperse $A \beta$ brain accumulation, impairing the amyloidogenic cascade and decreasing the pathological process. Also in AD research, sialic acid - PAMAM conjugates were prepared to mimic the cell surface gangliosides known to have affinity for $A \beta$. This resulted in a lower toxicity induced by $A \beta$, leading to higher cell viability in a differentiated neuronal cell culture since the sialic acid PAMAM functioned as a sequestering agent for $A \beta .86$ This suggests that specific dendrimer modifications may further enhance their ability to interact with abnormal $A \beta$. Another study using PPI glycodendrimers with either an electroneutral or a cationic maltose shell reduced in vitro the neurotoxicity of $A \beta$.[23] These two PPI maltose dendrimers reach the brain when administered intranasally and decrease the total burden of $A \beta$ in transgenic AD mice. However, the PPI dendrimer with a cationic maltose shell induced an unexpected and unexplained cognitive decline in non transgenic control mice. On the other hand, the electroneutral maltose dendrimer did not show any harmful effects to the mice used in this study. This highlights the fact that it is always important to exclude possible neurotoxic effects and, preferably, to perform tests using different methodologic approaches as well as assessments at different time points.

Another possible application of dendrimers in neurodegenerative diseases has been explored in the context of PD. PD is a degenerative neurological disorder which affects neurons expressing dopamine in the substancia nigra of the brain, leading to motor symptoms. The therapeutic effect of human glial - cell - line - derived neurotrophic factor (hGDNF) complexed with a G5 PAMAM and targeted with Lf has been assessed in two different PD models (the 6 - hydroxydopamine (6 - OHDA) and the rotenone - induced chronic model).[22, 75] Behavior recovery with improvement of locomotor activity, reduction of dopaminergic neurodegeneration, and enhancement of monoamine neurotransmitter levels were achieved after i.v. administration, without changes in monocytes/macrophage levels as a toxicity evaluation parameter. Another strategy in PD for effective brain - targeting gene delivery is the use of DGL bound with the angiopep - 2 ligand recognized by the $L R P 1$, which is widely expressed on $B B B$ endothelial cells. Multiple intraperitoneal injections of nanoparticles transporting a gene encoding for hGDNF resulted in improved locomotor 
activity without changes in body weight.[24] All these reports show promising data in the treatment of PD.

\title{
6.3 Neuroimmunomodulation
}

The noteworthy ability of PAMAM dendrimers to target neuroinflammatory cells, even without specific ligands, has led to some interesting applications.22 As an example, the therapeutic NAC was delivered i.v. in a rabbit model of cerebral palsy using PAMAM as delivery vector. NAC in a soluble form did not show protective effects, while a lower dose of NAC associated to $\mathrm{G}_{4}$ PAMAM - OH dendrimer was able to protect the brain by specifically reaching activated microglia and astrocytes, diminishing neuroinflammation and, consequently, protecting neurons.[22] This was ultimately shown to increase motor function of the animals. Moreover, this study also suggests that besides the influence of surface modifications that dictate the interactions of the dendrimers with distinct cells, the disease state and stage of pathology may as well influence the extent of the dendrimers uptake by different cells. The same compound, NAC, was also systemically delivered by PAMAM - OH dendrimers in a mouse model of neonatal brain injury showing a shift in dendrimer co - localization during the first 5 days from astrocytes and oligodendrocytes to activated microglia.[22] Unfortunately, the neuronal population was not assessed in this study.

Vaccines for CNS infections are another area where dendrimers have been applied with interest. This is the case for rabies, a neurotropic infection, where PETIM dendrimers were selected to complex with the rabies virus glycoprotein gene. 28 These dendriplexes were used to immunize mice after intramuscular administration with success since the viral titters of the nanoformulation were significantly increased when compared to control mice immunized with only the plasmid - based rabies vaccine. Additionally, after an intracerebral rabies virus challenge, mice treated with the dendriplex showed $100 \%$ survival in contrast to the $60 \%$ survival for the control delivery without the dendrimer.

\subsection{Neuroinfection}

Dendrimers are also recognized in various publications as having therapeutic activity against prion diseases.[22, 27, 87] This disease in humans, called Creutzfeldt-Jakob disease (CJD), is caused by the accumulation of abnormal prion proteins that usually affect the occipital cortex, cerebellum, and supranuclear pathways leading to CNS dysfunction. In these studies, different dendrimers (PAMAM, PPI, PEI and with different generations ranging from $\mathrm{G}_{3}$ to $\mathrm{G}_{5}$ ) were used. Dendrimers have been found to be beneficial in this context by eliminating prion protein in scrapie form from cells, although requiring high density of reactive surface groups in the dendrimer composition irrespective of its charge as stated by McCarthy and colleagues.88

Also regarding infection, HIV - 1 can cause dementia when the virus reaches the CNS. Antiretroviral therapy does not reach the CNS as readily as to other systems, 89 which has an impact on the CNS infection. The use of gene therapy with siRNA delivery mediated by dendrimers has been investigated. Carbosilane dendrimers were already successfully evaluated in different in vitro experiments for the delivery of siRNA to decrease viral activity[25] as well as in vivo, after a retro orbital vein injection, showing a very good biodistribution in the brain.[25] However, it remained to be determined if in vivo these dendriplexes would achieve gene - silencing levels similar to what was observed in human primary astrocytes cultures.

\author{
.
}




\subsection{CNS Tumors}

In the CNS, diverse tumors can be found, which include various gliomas, meningioma, choroid plexus carcinoma, medulloblastoma, and others, depending on the localization and the cell type from which it arises. Some have a very poor prognosis, such as the glioblastoma multiforme, the most malignant form of brain tumors. The use of dendrimers as delivery vectors for anti - cancer therapy, including brain tumors, is extensive, as previously referred. The radioisotope boron - 10 was one of the first cargos delivered by dendrimers to brain tumorsgo and although the in vitro results were promising in vivo, the study showed no specificity to the brain tumor cells, which is crucial in tumor therapy, that is, the requirement for selective cancer cell targeting. Therefore, different strategies were then employed such as the use of VEGF co - delivered in boronated dendrimersg1 and, onwards, the use of selective tumor - targeting moieties became common in dendrimer - based anti - cancer therapies. Various agents have been delivered or co - delivered with dendrimers, such as the cytotoxic drug methotrexate,66 Dox,50 docetaxel,[23] or paclitaxel.92 Also, therapeutic genes in brain cancer such as apoptin,93 interferon beta (IFN - $\beta$ ), 77 and pORF - hTRAIL[24] have also been delivered through dendrimers. The latter study, performed by Jiang group, is particularly interesting because it proposed a co - delivery system administered by i.v. injection, combining both gene and chemotherapy. Another interesting use for dendrimers in brain tumors is the application of polyvalent, dendrimer - bearing, magnetic nanoparticles ("dendriworm"), to deliver EGFR siRNA in a transgenic murine model of glioblastoma.94 For dendriworms development, cystamine core $\mathrm{G}_{4}$ PAMAM dendrimers were reduced, yielding thiol dendrons. Then, amine - modified, cross - linked strings of spherical iron oxide nanoparticles coated with a biocompatible polymer (Dextran), named "nanoworms", were prepared. Finally, reduced dendrons and nanoworms were conjugated using the heterobifuctional SPDP linker.94 Initially, dendriworms were administered via tail vein injections, but in this manner they accumulated significantly in the lungs. Subsequently, dendriworms were applied by CED. This methodology is highly invasive; nevertheless, the delivered dendriworms could diffuse in the brain parenchyma and deliver siRNA into the tumor cells, leading to significant gene suppression.

As already referred, a systemic delivery of dendrimers has been successful in various brain tumor models.[22, 75] A pharmacokinetic study using PAMAM - $\mathrm{OH}$ dendrimers showed a tumor accumulation only $15 \mathrm{~min}$ after tail vein injection, and it reached a peak concentration at 8 hours. The presence of the fluorescently labelled dendrimers was sustained for at least 48 hours.[22] Moreover, the dendrimers homogeneously distributed throughout solid tumor and gradually accumulate in tumor - associated microglia/macrophages, which might be relevant for the further delivery of immunomodulatory molecules.

\subsection{Spinal Cord Injury}

$\mathrm{SCl}$ after a mechanical trauma causes major disabilities in virtually all physical and functional systems. Furthermore, the majority of affected people are young adults, which puts extra pressure in the treatment and rehabilitation process. Various therapies are in the forefront trials and, as recently stated, the therapy should encompass a combinatorial approach to a recognized multifactorial problem.95 A dendrimer - based nanomedicine approach with all the advantages previously stated may be the most appropriate choice in $\mathrm{SCl}$ because it can offer multifunction abilities. Nevertheless, such studies have not been explored much to date. 
In the literature, a surface - engineered CMCht/PAMAM dendrimer was used to deliver a corticosteroid in a $\mathrm{SCl}$ animal model.96 This was performed by a local injection, $1 \mathrm{~mm}$ rostral and 1 $\mathrm{mm}$ caudal, to the partially hemisected spinal cord lesion, which allowed for a sustained and controlled release in glial cells at the injury site for 14 days. There was also an improvement in the functional outcome of the injured rats. Before in vivo administration, cytotoxicity was evaluated without significant effects in non - neuronal cells.

Other studies are now anticipated in the area of $\mathrm{SCl}$ therapies using dendrimers as the deliver vector, possibly carrying a combination of therapies intended to achieve neuroprotection and/or neuroregeneration effects.

\subsection{Other CNS Disorders}

As observed in previous examples, the PAMAM dendrimers are usually the first choice as a delivery vector. In accordance, G4 PAMAM - $\mathrm{OH}$ dendrimers have been applied in two rat models of retinal degeneration, resulting in cellular localization in activated microglia without the need of a cell specific ligand.[22] The drug fluocinolone acetonide, covalently conjugated to this dendrimer, as detailed above, was released in a sustained manner and, after a single retinal administration, dendrimers remained in the target cells for a remarkable period of over one month, effectively reducing inflammation. Such a controlled release is impressive and very appealing for this and other therapeutic purposes.

\subsection{Macromolecular Contrast Agents and Nanosensors}

Dendrimers are regarded in many different perspectives, depending on its function. Either they are being explored as vectors for delivery, antiviral agents, or even detoxifying compounds. Dendrimers have also been considered as macromolecular contrast agents and nanosensors for non - invasive, advanced neuroimaging. This was explored in the field of CNS bioimaging, with an optical paramagnetic contrast agent based on a G5 PAMAM dendrimer, which was successfully applied in a glioblastoma mice model.97 Such use may have impact in delineating the brain tumor for surgical removal. Regarding potential brain tumor diagnosis applications, a more efficient contrast agent based on Gd - DTPA for MRI that used DGLs was developed. For tumor specificity, the CTX peptide was used to target the nanoparticles, showing an ability to preferentially bind tumor cells.

The application of dendrimers as nanosensors was demonstrated using a G2 PEG - PAMAM for fluorescence sensing, which allowed monitoring changes of brain $\mathrm{pH}$ in vivo, as it was shown in a mice model of epilepsy.98 This new dendrimer - based sensor can have various applications depending on the conjugated sensing fluorophores, which should be relevant for dynamic in vivo measurements of various CNS disorders.

Also, a sodium - sensing nanosensor was produced that demonstrated efficacy in imaging neuronal activity in brain slices 65 and appeared better than available ion - sensitive probes based on small fluorescent dyes.

In a model of spinal cord contusion injury, the use of $\mathrm{G}_{1}$ fluorescent phosphorus - based dendrimers was useful in following bone - marrow - derived macrophages because such dendrimers are readily internalized and maintained by these inflammatory cells. After injection at the subarachnoid space,

(1) 
the macrophages were detected at the lesion site, and the dendrimers allowed assessing its phenotypic status because spectral changes in the phosphorus dendrimer emission profile were observed and related to the macrophage polarization physiology.99

\title{
7 Challenges and Future Perspectives
}

Dendrimers are nanosized materials that, due to their particular controlled globular structure, nanosize, multivalency, and low polydispersity are emerging in a large number of biomedical therapeutic applications. Besides the diagnosis and/or in vitro dendrimer - based products already in the market, dendritic systems have already reached the clinical evaluation as contrast - enhancer magnetic resonance imaging agents (Gadomer ${ }^{\circledR}-17$ ), anti - microbicides (Vivagel ${ }^{\circledR}$ ), and drug carriers for solid tumors therapy (DEP ${ }^{\mathrm{TM}}$ docetaxel). Notwithstanding, despite all these documented applications, the use of dendrimers within the CNS is still in its infancy and there are no reports of marketed products or current clinical trials using dendrimers for CNS diseases therapy.

One of the most significant challenges in CNS disease therapy is the ability of therapeutic bioactives to permeate the BBB and reach CNS in an adequate bioavailability.100 Due to their controllable nanosize, several reports have recognized the ability of dendrimers to permeate this barrier and gain access to the CNS after systemic administration. Moreover, dendrimers have not only shown potential to act by itself as therapeutic or theranostic agents but also as vectors for the protection and delivery of bioactives to the CNS (as summarized in Table 1). However, the proper in vivo dendrimer biodistribution and safety profile is yet to be determined in depth, which may hinder their passage for clinical evaluation.

Nonspecific dendrimer toxicity is closely related to its internal chemical composition, size, generation, and concentration, but it is mostly influenced by the nature of the surface terminal groups. In general, unmodified cationic dendrimers are more cytotoxic than their anionic or neutral counterparts.101 Likewise, higher concentrations and generations of unmodified cationic dendrimers display an inherently greater cationic surface charge and, therefore, a marked cytotoxic and hemolytic effect.102 However, there is still some inconsistency in the literature regarding the impact of the generation of a specific dendrimer on its toxicity profile. Namely, some authors have shown that low generations of PAMAM and PPI dendrimers are not toxic in vivo4, 103 (even if preliminary in vitro data has pointed to some toxicity profile), 56 while others have reported a toxic profile for the same dendrimers.104 This stresses the need for optimizing the dendrimer composition, generation, dosage, and administration route, as well as to assess the safety and effectiveness at different time points after administration.

Previous studies showed that unmodified cationic dendrimers, as well as other cationic macromolecules, strongly interact with the negatively charged cell membranes, which may destabilize membrane integrity followed by leakage of intracellular components that leads to cell death and toxicity.105 Moreover, when systemically administered, the cationic terminal groups of unmodified dendrimers can interact with red blood cells (RBCs), which may result in hemolysis. Similarly, such cationic dendrimers can also influence hematological parameters such as white blood cell (WBC) and RBC counts and morphology, hemoglobin content, and hematocrit and mean corpuscular hemoglobin ( $\mathrm{MCH}$ ) values.106 Thus, the prevention of strong electrostatic interactiTableons of dendrimers or bioactive/dendrimer system with cellular membranes by use of neutral or anionic dendrimers and/or by surface engineering (e.g., by the well - known PEGylation

\author{
.
}


and/or carbohydrate coating) is a step that must be carefully considered to minimize nonspecific

toxicity.

For instance, Greish et al. compared the toxicity profile of hydroxyl and carboxyl - terminated PAMAM dendrimers with the amine - terminated counterparts. Both neutral hydroxyl and anionic carboxyl - terminated PAMAM dendrimers showed a decrease in their cytotoxic profile, with no evidence of causing protein opsonization or blood hemolysis, as compared to amine - terminated PAMAM.[101] The same findings were corroborated by others.107 Overall, these studies demonstrate that the use of neutral and anionic dendrimers together with surface engineering strategies are key tools to enhance biocompatibility and reduce the overall immunogenicity of these systems. Additionally, another strategy capable of modulating the biocompatibility of dendritic systems is the optimization of their size. As previously discussed, the size of dendrimers or dendrimer/bioactive systems can be finely tuned to maximize, for example, the EPR effect or rapid in vivo clearance, accordingly to the proposed application.

Dendrimers' biodistribution is predominantly modulated by their size and surface chemistry. While smaller dendrimers present short circulation times and are more quickly cleared by renal filtration, bigger dendrimers are slowly eliminated from the circulation and are more efficiently taken up by macrophages, leading to increased reticulo - endothelial system (RES) clearance.108 Moreover, cationic dendrimers have the potential to interact more strongly with vasculature of highly perfused organs, which increases their clearance rate from the circulation as compared to anionic equivalents.[107]

The above - mentioned surface engineering with shielding agents or targeting ligands may not only aim at diminishing the charge - dependent toxicity but also increase water solubility and circulation time (especially when systems modified with anti - biofouling polymers, like PEG, are explored) while minimizing off - target effects by enhancing the systems targeting potential and payload efficacy. For example, Zhu and co - workers demonstrated that increasing the degree of PEGylation in PAMAM dendrimers can reduce liver and spleen accumulation and general toxicity, prolong the circulation time, and enhance the accumulation in tumor tissue of the PEGylated dendrimers conjugates, as compared to their unmodified equivalents.[22] The impact of dendrimer PEGylation on its biodistribution and circulation time was recently corroborated by Kojima et al.109 Moreover, other promising anti - biofouling/non - fouling polymers have recently emerged as possible alternatives to PEG, namely zwitterionic polymers,110 poly(2 - oxazoline)s,[110, 111] poly(peptoids), [110] and poly(carbonates), 112 among others. Although there are already a few works in which some of these polymers are linked to dendritic structures, $[110,111]$ further studies are expected to test the favorable properties of these alternative polymers when attached to dendrimers.

Similarly, Kesharwani et al. compared the tumor targeting potential and respective toxicity profile of three different ligand - conjugated PPI dendrimers with the corresponding plain (unmodified) PPI counterparts. They observed that the receptor conjugated PPI dendrimers not only showed enhanced tumor - targeting potential, but also significantly diminished hemolytic toxicity as compared with the plain PPI dendrimers.113

Within the CNS applications, the BBB permeation ability of dendrimers can be seen as a double edged sword. While the enhanced BBB permeation may increase the bioavailability of therapeutic bioactives within the CNS, it can also increase the risks of overexposure of target cells to the

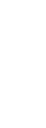


therapeutic bioactives and dendrimers and, consequently, result in CNS toxicity. This cell toxicity is a feature commonly associated with the use of non - biodegradable dendrimers. Non - biodegradable dendrimers have the potential for long - term accumulation within lysosomes or cytoplasm and thus exhibit undesired cytotoxicity effects, which may be the case for reactive oxygen species (ROS) production and decreased metabolic activity.114 Therefore, to prevent dendrimer bioaccumulation - associated toxicity, the use of biodegradable dendrimers is strongly encouraged in a biomedical scenario.115 Such dendrimers should degrade into smaller fragments under physiological conditions, which can be excreted or eliminated through metabolic pathways.

Despite the intensive evaluation of dendrimers in the past few years, much research remains to be done to allow the ready translation of these nanoconstructs into clinically useful CNS nanomedicines. It is now clear that the potential benefit of dendrimers is closely linked to their physicochemical properties, which should be modulated in accordance with the proposed therapeutic application. However, this review clearly depicts the poor variability of dendrimer classes that underwent preclinical evaluation. For application in the CNS, the majority of the dendrimers used were based only in 3 main families: PAMAM, PPI, and PLL dendrimers. Consequently, future developments towards the design of more biocompatible and biodegradable dendrimers, novel linker technologies, as well as novel targeting agents that can collectively result in the improvement of dendrimer - based systems bioavailability at the target tissues, are eagerly awaited. Furthermore, efforts on the development of efficient multigram synthesis to fulfill the pharmaceutical industry demand, as well as green synthetic routes, will also be important to the field. Minimizing the use and generation of hazardous substances would have an impact not only in environmental terms but would also contribute to improvements in terms of purification processes and biocompatibility. The design of such improved systems will therefore require additional efforts to better understand the dendrimer - cell/body interaction, as well as their in vivo fate. Nevertheless, resolution and lack of sensitivity of currently available bioimaging tools remains a caveat when studying nanosystems behavior at the whole - body scale.116 At present, the field has been limited to the evaluation of overall biodistribution/accumulation in key organs, time of clearance, systemic inflammatory reaction and associated toxicity.

When considering the CNS, the possibility to explore several routes of administration (Figure 1) opens new avenues to improve the efficiency and, when applicable, the targeting of the treatment. However, for many neurological disorders the etiology and the specificities of the disease are yet poorly understood. So, the field will have to be constantly fed from the progress achieved at the fundamentals of neuroscience and neurology.

All in all, successfully bringing forward dendrimers as powerful tools in the treatment of CNS diseases will definitely require a multi - and interdisciplinary effort due to the uniqueness and paramount importance of this system.

In conclusion, dendrimers can be used in the CNS with various purposes, not only to deliver active therapeutic molecules but also to assess brain function and to diagnose CNS diseases or even to perform a combination of these purposes. Such a remarkable ability highlights their tremendous potential as a precise theranostic multifunctional agent, which we predict in the future to be extended to other unexplored CNS disorders. 


\section{Acknowledgements}

$\checkmark$ Leiro, SD Santos, and CDF Lopes contributed equally to this work. The authors would like to acknowledge the financial support of the Fundo para a Investigação em Saúde (INFARMED, project reference FIS - 2015 - 01_CCV_20150630 - 88), as well as the FEDER funds through the Programa Operacional Competitividade e Internacionalização - COMPETE 2020 and the Portuguese funds through FCT - Fundação para a Ciência e a Tecnologia in the frame of the project POCI - 01 - 0145 FEDER - 016639 (reference PTDC/CTM - NAN/3547/2014). SD Santos is supported by FCT funds (SFRH/BPD/109297/2015). V Leiro is supported by the project NORTE - 01 - 0145 - FEDER 000012 , financed by Norte Portugal Regional Operational Programme (NORTE 2020), under the PORTUGAL 2020 Partnership Agreement, through the European Regional Development Fund (ERDF).

\section{Conflict of Interest}

The authors declare no conflict of interest.

Table 1. Overview of dendrimer applications in the context of the CNS

$\begin{array}{llllll} & \text { Dendrimer } & \text { Targeting } & \text { Bioactive } & \text { Remarks } & \text { Reference } \\ \text { family } & \text { ligand } & \text { agent } & \text { s }\end{array}$

\section{Vascular diseases}

Ischemic stroke

PAMAM

n.a.

HMGB1 Reduction of

$\left(G_{2}, G_{4}\right)$

SiRNA,

infarction in the

pHO-1 ischemic brain

Ischemic stroke

(

PHO-1

$$
\text { ischemic brain }
$$

\section{Preferable}

$\operatorname{DGL}\left(G_{3}\right)$

$\begin{array}{ll}\text { Dermorphi } & \text { anti-Ask1 } \\ \mathrm{n} & \text { shRNA }\end{array}$

accumulation and gene transfection in brain

Significant reduction of cerebral infarct area 


\begin{tabular}{|c|c|c|c|c|c|}
\hline Application & $\begin{array}{l}\text { Dendrimer } \\
\text { family }\end{array}$ & $\begin{array}{l}\text { Targeting } \\
\text { ligand }\end{array}$ & $\begin{array}{l}\text { Bioactive } \\
\text { agent }\end{array}$ & Remarks & $\begin{array}{l}\text { Reference } \\
\text { s }\end{array}$ \\
\hline $\begin{array}{l}\text { Hypoxia-mediated } \\
\text { neurotoxicity }\end{array}$ & $\begin{array}{l}\text { Carbosilan } \\
\text { e (G2) }\end{array}$ & n.a. & $\begin{array}{l}\text { HIF1- } \alpha \\
\text { siRNA }\end{array}$ & $\begin{array}{l}\text { In vitro selective } \\
\text { block of HIF }\end{array}$ & [25] \\
\hline $\begin{array}{l}\text { Hypothermic } \\
\text { circulatory arrest }\end{array}$ & $\begin{array}{l}\text { PAMAM } \\
\left(G_{4}\right)\end{array}$ & n.a. & VPA, NAC & $\begin{array}{l}\text { Injured } \\
\text { crossing and } \\
\text { localization in } \\
\text { injured } \\
\text { hippocampal } \\
\text { dentate granule } \\
\text { cells, cerebellar } \\
\text { Purkinje and } \\
\text { granule cells and } \\
\text { microglia }\end{array}$ & [22] \\
\hline & & & & $\begin{array}{l}\text { Improvement of } \\
\text { neurobehavioral } \\
\text { outcomes }\end{array}$ & \\
\hline
\end{tabular}

Neurodegenerative diseases

Alzheimer

$\begin{array}{lll}\text { PPI } & \left(G_{4}, \quad \text { n.a. }\right. \\ \text { G5) } & \end{array}$

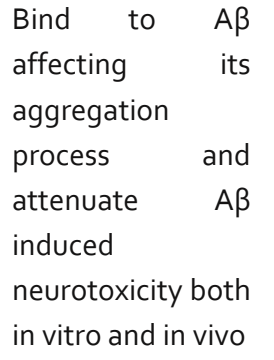

PAMAM

(Go, G3, 


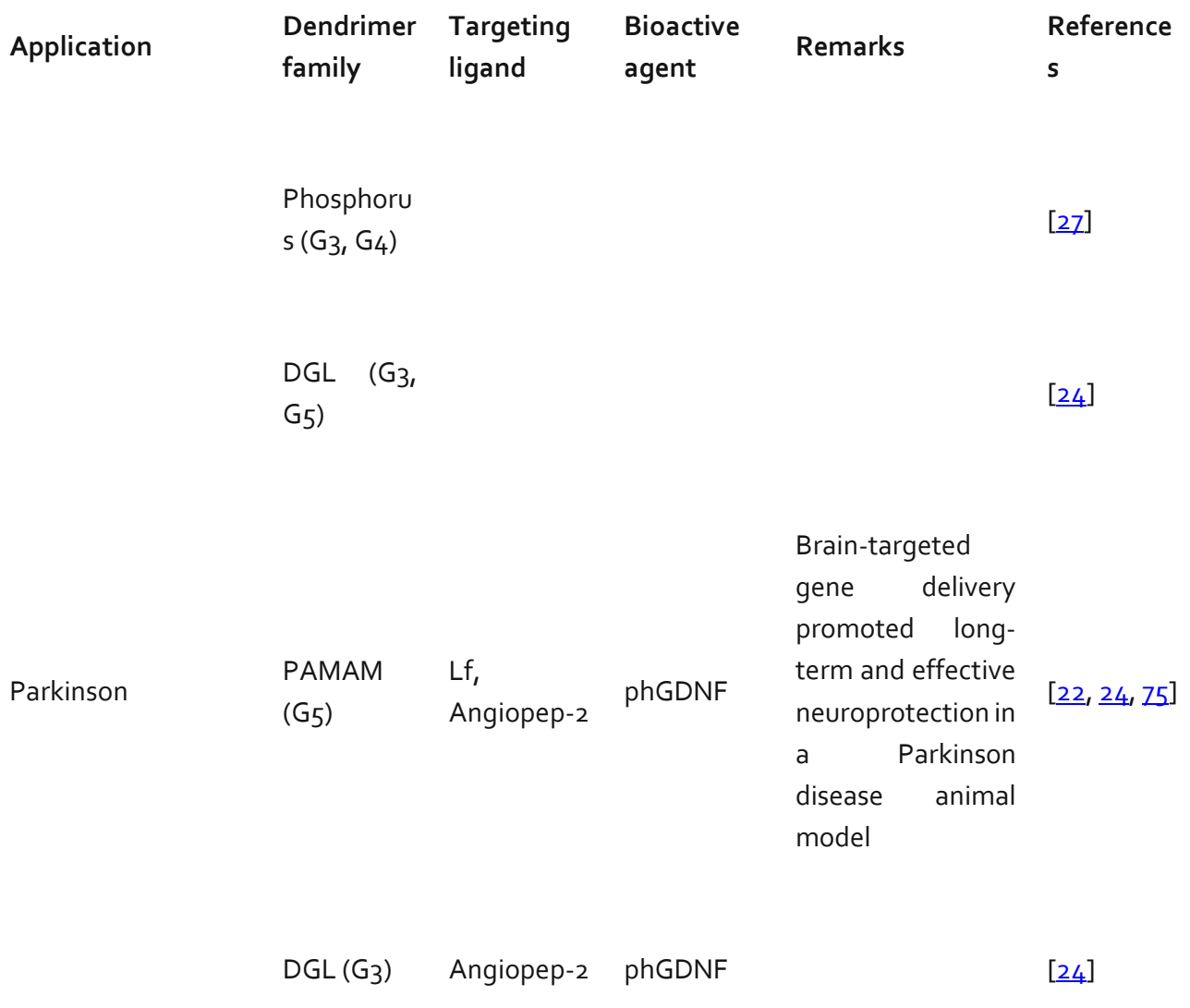

\section{Neuroimmunomodulation}

$\begin{array}{llll} & & \text { Accumulation in } \\ \text { Cerebral palsy } & \text { PAMAM n.a. NaC } & \begin{array}{l}\text { activated } \\ \text { microglia } \\ \text { astrocytes }\end{array} \text { and [22] }\end{array}$

\footnotetext{
Suppression of neuroinflammatio n accompanied with motor function improvement
} 


$\begin{array}{llllll}\text { Application } & \begin{array}{l}\text { Dendrimer } \\ \text { family }\end{array} & \begin{array}{l}\text { Targeting } \\ \text { ligand }\end{array} & \begin{array}{l}\text { Bioactive } \\ \text { agent }\end{array} & \text { Remarks } & \text { Reference }\end{array}$

Attenuation of the pro-inflammatory

Ischemia-induced PAMAM

white matter injury $\quad\left(G_{4}\right)$

n.a. NAC

response while not

impacting the

[22]

anti-inflammatory

response

Produce an earlier

Vaccines

PETIM

(G4)

n.a.

pIRES-Rgp

onset of a hightittered protective antibody response

n.a. vivo

PPI (G4,

G5)

G5)

Rev AON,

GEMg1

AON, anti- General decrease TAR AON, of antiviral activity

HIV-1 infection

Carbosilan e (G2) n.a. p24 SiRNA,

nef siRNA both in vitro and in vivo

and Cox-2

siRNA

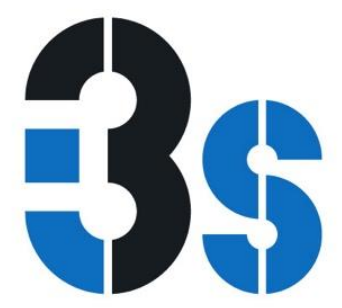

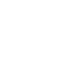

8




\begin{tabular}{|c|c|c|c|c|c|}
\hline Application & $\begin{array}{l}\text { Dendrimer } \\
\text { family }\end{array}$ & $\begin{array}{l}\text { Targeting } \\
\text { ligand }\end{array}$ & $\begin{array}{l}\text { Bioactive } \\
\text { agent }\end{array}$ & Remarks & Reference \\
\hline
\end{tabular}

\section{Cancer}

Glioma/Glioblastom

a

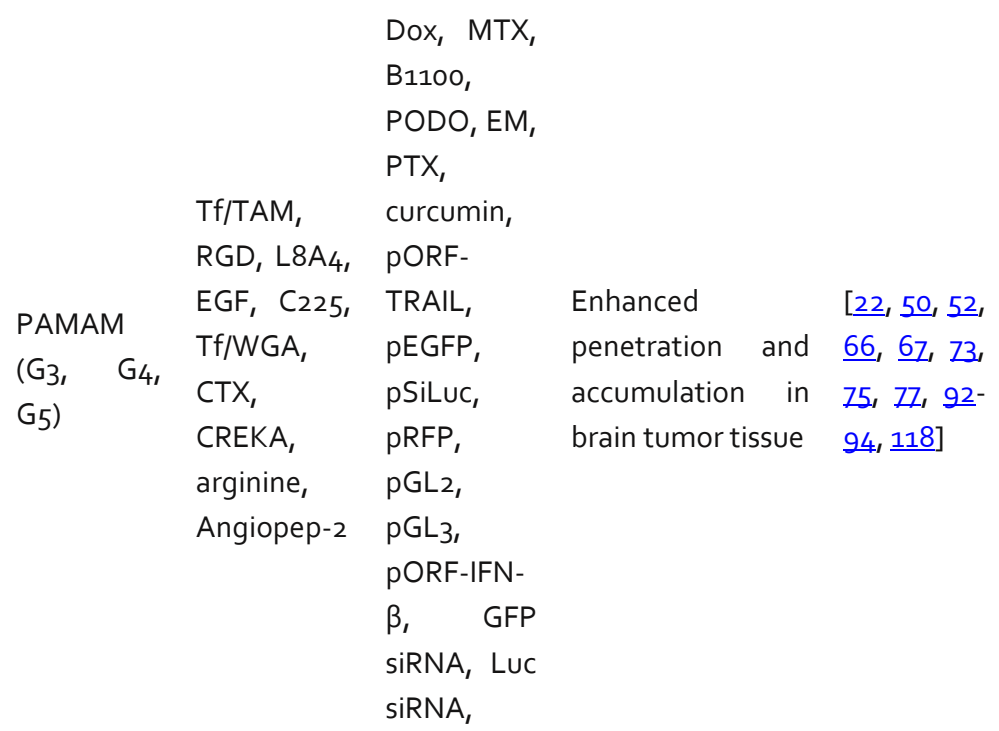

$\left(G_{3}, G_{4}\right.$,

Anti-tumor effect

D-

$\operatorname{PEPE}\left(\mathrm{G}_{2}\right) \quad$ glucosamin $\mathrm{MTX} \quad \underline{26}$

$\begin{array}{lll}\text { PPI (G5) } & \begin{array}{l}\text { P8o, } \\ \text { thiamine }\end{array} & \text { DTX, PTX } \\ & & \\ & & \text { pORF- } \\ & \text { T7 peptide, } & \text { TRAIL, } \\ \text { DGL (G3) } & \text { cyclic RGD } & \text { Dox, Luc } \\ & & \text { siRNA }\end{array}$

$[\underline{23}]$

Spinal cord injury Version: Postprint (identical content as published paper) This is a self-archived document from i3S - Instituto de
Investigação e Inovação em Saúde in the University of Porto Open Repository For Open Access to more of our publications, please visit http://repositorio-aberto.up.pt/ 


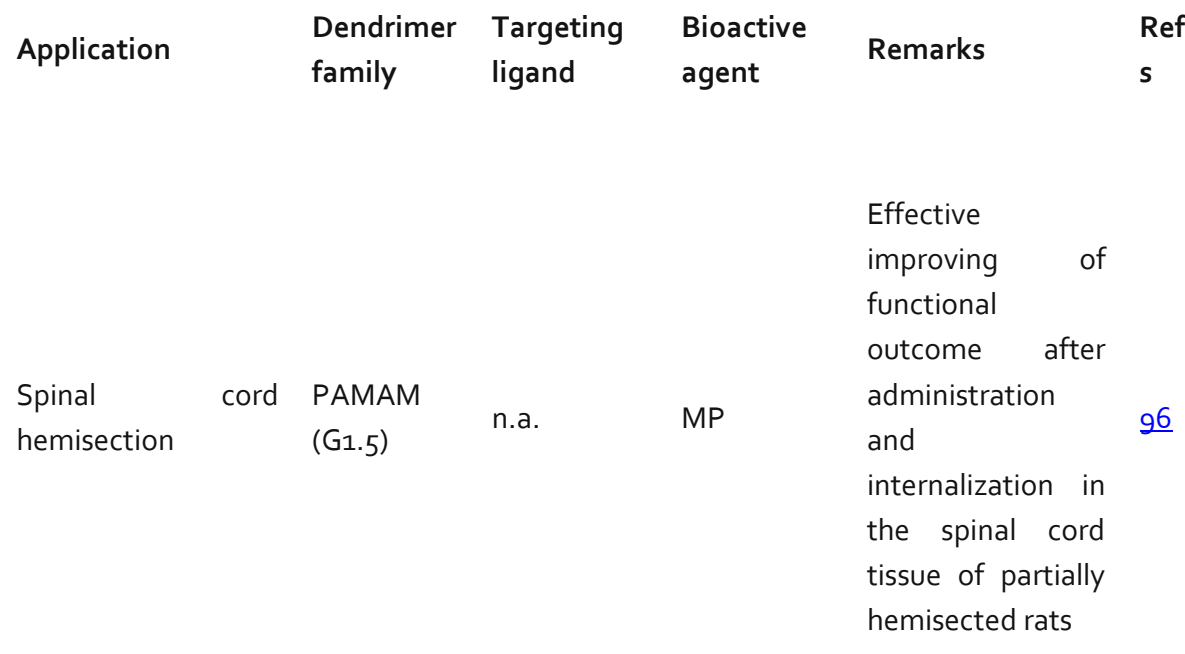

\section{Other applications}

$\begin{array}{lll}\text { Retinal } & \text { PAMAM } & \\ \text { degeneration } & \left(\mathrm{G}_{4}\right) & \text { n.a. }\end{array}$

Accumulation in the outer retina within activated microglia without active targeting

Reference

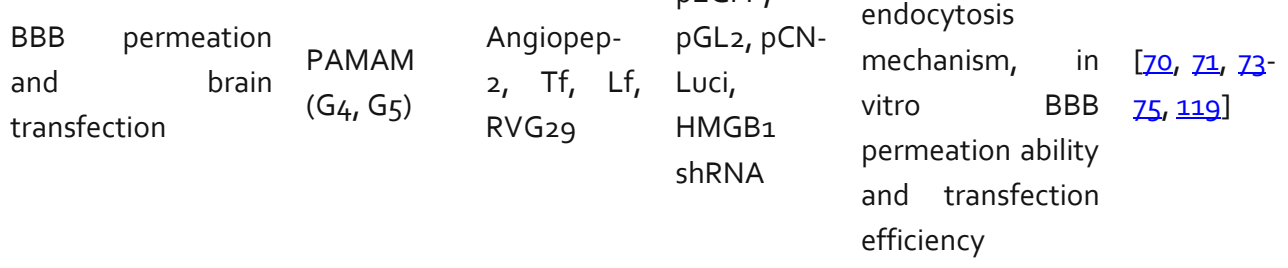




\begin{tabular}{|c|c|c|c|c|c|}
\hline \multirow[t]{3}{*}{ Application } & $\begin{array}{l}\text { Dendrimer } \\
\text { family }\end{array}$ & $\begin{array}{l}\text { Targeting } \\
\text { ligand }\end{array}$ & $\begin{array}{l}\text { Bioactive } \\
\text { agent }\end{array}$ & Remarks & $\begin{array}{l}\text { Reference } \\
\text { s }\end{array}$ \\
\hline & $\begin{array}{l}\mathrm{PPI} \quad\left(\mathrm{G}_{3},\right. \\
\left.\mathrm{G}_{4}\right)\end{array}$ & Tf & $\begin{array}{l}\text { pCMVsport } \\
\beta \text {-gal, } \\
\text { pCMV- } \\
\text { tdTomato }\end{array}$ & & {$[\underline{10}, \underline{23}]$} \\
\hline & DGL & Leptin 30 & pRFP & & {$[\underline{22}]$} \\
\hline Toxicity & $\begin{array}{l}\text { PAMAM } \\
\left(G_{4}\right)\end{array}$ & n.a. & n.a. & $\begin{array}{l}\text { Proof of concept: } \\
\text { in vitro and in vivo } \\
\text { toxicity }\end{array}$ & 4,78 \\
\hline
\end{tabular}

\section{Contrast agents and nanosensors}

\begin{tabular}{|c|c|c|c|c|c|}
\hline Contrast agents & $\begin{array}{c}\text { PAMAM } \\
\left(G_{5}\right)\end{array}$ & Angiopep-2 & $\begin{array}{l}\text { Rhodamine } \\
\text {,Cy5.5 and } \\
\text { Gd(III)- } \\
\text { DOTA }\end{array}$ & $\begin{array}{l}\text { Conjugation of } \\
\text { MR and optical } \\
\text { reporters to be } \\
\text { used as contrast } \\
\text { agents. Ability to } \\
\text { circumvent the } \\
\text { blood brain } \\
\text { barrier (BBB) and } \\
\text { visualize brain } \\
\text { tumors with high } \\
\text { sensitivity in vivo }\end{array}$ & 97 \\
\hline & & & Fluorescein & & \\
\hline Sensor & $\begin{array}{c}\text { PAMAM } \\
\left(G_{2}, G_{4} \cdot 5,\right. \\
\left.G_{5}\right)\end{array}$ & n.a. & $\begin{array}{l}\text { ' } \\
\text { rhodamine, } \\
\text { CoroNa } \\
\text { (Green or } \\
\text { Red) }\end{array}$ & $\begin{array}{l}\text { Ability to monitor } \\
\text { changes of } \\
\text { neuronal activity } \\
\text { and brain } \mathrm{pH}\end{array}$ & 65,98 \\
\hline
\end{tabular}




$\begin{array}{llllll}\text { Application } & \begin{array}{l}\text { Dendrimer } \\ \text { family }\end{array} & \begin{array}{l}\text { Targeting } \\ \text { ligand }\end{array} & \begin{array}{l}\text { Bioactive } \\ \text { agent }\end{array} & \text { Remarks } & \begin{array}{l}\text { Reference } \\ \text { s }\end{array} \\ \text { Phosphoru } & \text { n.a. } & \begin{array}{c}\text { Fluorophor } \\ \text { e (Em 485 } \\ \mathrm{nm}\left(\mathrm{G}_{1}\right)\end{array} & \begin{array}{c}\text { Ability to sensor } \\ \text { macrophage } \\ \text { phenotype }\end{array} & 99\end{array}$




\section{REFERENCES}

[1] W. H. Organization, Neurology and public health, http://www.who.int/mental_health/neurology/en/ (accessed: December 2016).

[2] J. H. Chin, N. Vora, Neurology 2014, 83, 349.

[3] F. Bradke, J. W. Fawcett, M. E. Spira, Nat. Rev. Neurosci. 2012, 13,183.

[4] L. Albertazzi, L. Gherardini, M. Brondi, S. S. Sato, A. Bifone, T. Pizzorusso, G. M. Ratto, G. Bardi, Mol. Pharmaceut. 2013, 10, 249.

[5] B. Obermeier, R. Daneman, R. M. Ransohoff, Nat. Med. 2013, 19, 1584.

[6] R. Gabathuler, Neurobiol. Dis. 2010, 37, 48.

[7] W. A. Banks, BMC Neurol. 2009, 9 Suppl 1, S3.

[8] W. Lu, Curr. Pharm. Biotechnol. 2012, 13, 2340.

[9] S. Mignani, M. Bryszewska, M. Zablocka, B. Klajnert-Maculewicz, J. Cladera, D. Shcharbin, J.-P. Majoral, Prog. Polym. Sci. 2017, 64, 23.

[10] a) C. Dufes, M. Al Robaian, S. Somani, Ther. Delivery 2013, 4, 629; b) S. Somani, D. R. Blatchford, O. Millington, M. L. Stevenson, C. Dufes, J. Controlled Release 2014, $188,78$.

[11] C. Y. Lin, H. Y. Hsieh, W. G. Pitt, C. Y. Huang, I. C. Tseng, C. K. Yeh, K. C. Wei, H. L. Liu, J. Controlled Release $2015,212,1$.

[12] a) D. Knowland, A. Arac, K. J. Sekiguchi, M. Hsu, S. E. Lutz, J. Perrino, G. K. Steinberg, B. A. Barres, A. Nimmerjahn, D. Agalliu, Neuron 2014, 82, 603; b) R. Prakash, S. T. Carmichael, Curr. Opin. Neurol. 2015, 28, 556.

[13] a) P. J. Gaillard, C. C. Appeldoorn, J. Rip, R. Dorland, S. M. van der Pol, G. Kooij, H. E. de Vries, A. Reijerkerk, J. Controled Release 2012, 164, 364; b) A. L. Cardoso, S. Simoes, L. P. de Almeida, N. Plesnila, M. C. Pedroso de Lima, E. Wagner, C. Culmsee, J. Controlled Release 2008, 132, 113.

[14] a) P. Zhang, L. Hu, Q. Yin, Z. Zhang, L. Feng, Y. Li, J. Controlled Release 2012, 159, 429; b) K. Shao, J. Q. Wu, Z. Q. Chen, S. X. Huang, J. F. Li, L. Y. Ye, J. N. Lou, L. P. Zhu, C. Jiang, Biomaterials 2012, 33, 6898.

[15] a) O. Y. Zolotarskaya, A. F. Wagner, J. M. Beckta, K. Valerie, K. J. Wynne, H. Yang, Mol. Pharmaceutics 2012, 9, 3403; b) G. P. Tang, J. M. Zeng, S. J. Gao, Y. X. Ma, L. Shi, Y. Li, H. P. Too, S. Wang, Biomaterials 2003, 24, 2351

[16] a) X. L. Gao, J. Chen, J. Y. Chen, B. X. Wu, H. Z. Chen, X. G. Jiang, Bioconjugate Chemistry 2008, 19, 2189; b) A. Bonoiu, S. D. Mahajan, L. Ye, R. Kumar, H. Ding, K. T. Yong, I. Roy, R. Aalinkeel, B. Nair, J. L. Reynolds, D. E. Sykes, M. A. Imperiale, E. J. Bergey, S. A. Schwartz, P. N. Prasad, Brain Res. 2009, 1282, 142.

[17] a) A. Montagne, M. Gauberti, R. Macrez, A. Jullienne, A. Briens, J. S. Raynaud, G. Louin, A. Buisson, B. Haelewyn, F. Docagne, G. Defer, D. Vivien, E. Maubert, Neuroimage 2012, 63, 760; b) B. T. Farrell, B. E. Hamilton, E. Dosa, E. Rimely, M. Nasseri, S. Gahramanov, C. A. Lacy, E. P. Frenkel, N. D. Doolittle, P. M. Jacobs, E. A. Neuwelt, Neurology 2013, 81, 256. [18] J. Ren, S. Shen, D. Wang, Z. Xi, L. Guo, Z. Pang, Y. Qian, X. Sun, X. Jiang, Biomaterials 2012, 33, 3324 .

[19] a) L. Xu, H. Zhang, Y. Wu, ACS Chem. Neurosci. 2014, 5, 2; b) V. Mishra, P. Kesharwani, Drug Discov. Today 2016, 21, 766 .

[20] E. Buhleier, W. Wehner, F. Vogtle, Synthesis 1978, 2, 155.

[21] a) R. G. Denkewalter, J. Kolc, W. J. Lukasavage (Google Patents) Patent U.S. Patent 4289872, 1981; b) D. A. Tomalia, H. Baker, J. Dewald, M. Hall, G. Kallos, S. Martin, J. Roeck, J. Ryder, P. Smith, Polym. J. 1985, 17, 117; C) G. 
R. Newkome, Z. Q. Yao, G. R. Baker, V. K. Gupta, J. Org. Chem. 1985, 50, 2003; d) C. J. Hawker, J. M. J. Frechet, J. Am. Chem. Soc. 1990, 112, 7638 .

[22] a) Y. E. Kurtoglu, R. S. Navath, B. Wang, S. Kannan, R. Romero, R. M. Kannan, Biomaterials 2009, 30, 2112; b) I. D. Kim, C. M. Lim, J. B. Kim, H. Y. Nam, K. Nam, S. W. Kim, J. S. Park, J. K. Lee, J. Controlled Release 2010, 142, 422; c) P. Jeon, M. Choi, J. Oh, M. Lee, Macromol. Biosci. 2015, 15, 1021; d) M. K. Mishra, C. A. Beaty, W. G. Lesniak, S. P. Kambhampati, F. Zhang, M. A. Wilson, M. E. Blue, J. C. Troncoso, S. Kannan, M. V. Johnston, W. A. Baumgartner, R. M. Kannan, ACS Nano 2014, 8, 2134; e) I. D. Kim, J. H. Shin, S. W. Kim, S. Choi, J. Ahn, P. L. Han, J. S. Park, J. K. Lee, Mol. Ther. 2012, 20, 829; f) R. Huang, W. Ke, Y. Liu, D. Wu, L. Feng, C. Jiang, Y. Pei, J. Neurol. Sci. 2010, 290, 123; g) R. lezzi, B. R. Guru, I. V. Glybina, M. K. Mishra, A. Kennedy, R. M. Kannan, Biomaterials 2012, 33, 979; h) B. Wang, R. S. Navath, R. Romero, S. Kannan, R. Kannan, Int. J. Pharm. 2009, 377, 159; i) H. Dai, R. S. Navath, B. Balakrishnan, B. R. Guru, M. K. Mishra, R. Romero, R. M. Kannan, S. Kannan, Nanomedicine (Lond) 2010, 5, 1317; j) E. Nance, M. Porambo, F. Zhang, M. K. Mishra, M. Buelow, R. Getzenberg, M. Johnston, R. M. Kannan, A. Fatemi, S. Kannan, J. Controlled Release 2015, 214, 112; k) W. G. Lesniak, M. K. Mishra, A. Jyoti, B. Balakrishnan, F. Zhang, E. Nance, R. Romero, S. Kannan, R. M. Kannan, Mol. Pharmaceutics 2013, 10, 4560; I) S. Kannan, H. Dai, R. S. Navath, B. Balakrishnan, A. Jyoti, J. Janisse, R. Romero, R. M. Kannan, Sci. Transl. Med. 2012, 4, 130,130; m) I. Burd, F. Zhang, T. Dada, M. K. Mishra, T. Borbiev, W. G. Lesniak, H. Baghlaf, S. Kannan, R. M. Kannan, Nanomedicine 2014, 10, 1343; n) Y. Liu, J. Li, K. Shao, R. Huang, L. Ye, J. Lou, C. Jiang, Biomaterials 2010, 31, 5246; 0) S. Supattapone, H. Wille, L. Uyechi, J. Safar, P. Tremblay, F. C. Szoka, F. E. Cohen, S. B. Prusiner, M. R. Scott, J. Virol. 2001, 75, 3453; p) J. M. McCarthy, B. Rasines, D. Appelhans, M. Rogers, Adv. Healthcare Mater. 2012, 1, 768; q) K. Wang, X. Zhang, Y. Liu, C. Liu, B. Jiang, Y. Jiang, Biomaterials 2014, 35, 8735; r) F. Zhang, P. Mastorakos, M. K. Mishra, A. Mangraviti, L. Hwang, J. Zhou, J. Hanes, H. Brem, A. Olivi, B. Tyler, R. M. Kannan, Biomaterials 2015, 52, 507; s) S. Zhu, M. Hong, G. Tang, L. Oian, J. Lin, Y. Jiang, Y. Pei, Biomaterials 2010, 31, 1360; t) Y. Li, H. He, X. Jia, W. L. Lu, J. Lou, Y. Wei, Biomaterials 2012, 33, 3899; u) L. Zhang, S. Zhu, L. Qian, Y. Pei, Y. Qiu, Y. Jiang, Eur. J. Pharm. Biopharm. 2011, 79, 232; v) N. H. Gamage, L. Jing, M. J. Worsham, M. M. Ali, J. Nanomed. Nanotechnol. 2016, 7; w) J. Zhao, B. Zhang, S. Shen, J. Chen, Q. Zhang, X. Jiang, Z. Pang, J. Colloid Interface Sci. 2015, 450, 396.

[23] a) O. Klementieva, N. Benseny-Cases, A. Gella, D. Appelhans, B. Voit, J. Cladera, Biomacromolecules 2011, 12, 3903; b) O. Klementieva, E. Aso, D. Filippini, N. Benseny-Cases, M. Carmona, S. Juves, D. Appelhans, J. Cladera, I. Ferrer, Biomacromolecules 2013, 14, 3570; c) V. Gajbhiye, N. K. Jain, Biomaterials 2011, 32, 6213; d) S. K. Patel, V. Gajbhiye, N. K. Jain, J. Drug Targeting 2012, 20, 841; e) A. Janaszewska, B. Ziemba, K. Ciepluch, D. Appelhans, B. Voit, B. Klajnert, M. Bryszewska, New J. Chem. 2012, 36, 350.

[24] a) I. M. Neelov, A. Janaszewska, B. Klajnert, M. Bryszewska, N. Z. Makova, D. Hicks, H. A. Pearson, G. P. Vlasov, M. Y. Ilyash, D. S. Vasilev, N. M. Dubrovskaya, N. L. Tumanova, I. A. Zhuravin, A. J. Turner, N. N. Nalivaeva, Curr. Med. Chem. 2013, 20, 134; b) R. Huang, H. Ma, Y. Guo, S. Liu, Y. Kuang, K. Shao, J. Li, Y. Liu, L. Han, S. Huang, S. An, L. Ye, J. Lou, C. Jiang, Pharm. Res. 2013, 30, 2549; C) Y. Kuang, S. An, Y. Guo, S. Huang, K. Shao, Y. Liu, J. Li, H. Ma, C. Jiang, Int. J. Pharm. 2013, 454, 11; d) T. L. Kaneshiro, Z. R. Lu, Biomaterials 2009, 30, 566o; e) S. Liu, Y. Guo, R. Huang, J. Li, S. Huang, Y. Kuang, L. Han, C. Jiang, Biomaterials 2012, 33, 4907.

[25] a) I. Posadas, B. Lopez-Hernandez, M. I. Clemente, J. L. Jimenez, P. Ortega, J. de la Mata, R. Gomez, M. A. Munoz-Fernandez, V. Cena, Pharm. Res. 2009, 26, 1181; b) T. Gonzalo, M. I. Clemente, L. Chonco, N. D. Weber, L. Diaz, M. J. Serramia, R. Gras, P. Ortega, F. J. de la Mata, R. Gomez, L. A. Lopez-Fernandez, M. A. MunozFernandez, J. L. Jimenez, ChemMedChem 2010, 5, 921; C) M. J. Serramia, S. Alvarez, E. Fuentes-Paniagua, M. I. Clemente, J. Sanchez-Nieves, R. Gomez, J. de la Mata, M. A. Munoz-Fernandez, J. Controlled Release 2015, 200, 6o; d) J. L. Jimenez, M. I. Clemente, N. D. Weber, J. Sanchez, P. Ortega, F. J. de la Mata, R. Gomez, D. Garcia, L. A. Lopez-Fernandez, M. A. Munoz-Fernandez, BioDrugs 2010, 24, 331.

[26] R. S. Dhanikula, A. Argaw, J. F. Bouchard, P. Hildgen, Mol. Pharmaceutics 2008, 5, 105.

[27] a) T. Wasiak, M. Ionov, K. Nieznanski, H. Nieznanska, O. Klementieva, M. Granell, J. Cladera, J. P. Majoral, A. M. Caminade, B. Klajnert, Mol. Pharmaceutics 2012, 9, 458; b) J. Solassol, C. Crozet, V. Perrier, J. Leclaire, F. Beranger, A. M. Caminade, B. Meunier, D. Dormont, J. P. Majoral, S. Lehmann, J. Gen. Virol. 2004, 85, 1791.

INSTITUTO DE INVESTIIGAÇÃO E INOVAÇÄO EM SAÚDE UNIVERSIDADE DO PORTO

Rua Alfredo Allen, 208 4200-135 Porto Portugal +351220408800 
[28] P. T. Ullas, S. N. Madhusudana, A. Desai, B. K. C. Sagar, G. Jayamurugan, Y. B. R. D. Rajesh, N. Jayaraman, Int. J. Nanomed. 2014, 9, 627 .

[29] B. Klajnert, T. Wasiak, M. Ionov, M. Fernandez-Villamarin, A. Sousa-Herves, J. Correa, R. Riguera, E. Fernandez-Megia, Nanomedicine 2012, 8, 1372.

[30] a) Y. Y. Cheng, Z. H. Xu, M. L. Ma, T. W. Xu, J. Pharm. Sci. 2008, 97, 123; b) S. Mignani, S. El Kazzouli, M. Bousmina, J. P. Majoral, Adv. Drug Delivery Rev. 2013, 65, 1316.

[31] A. R. Menjoge, R. M. Kannan, D. A. Tomalia, Drug Discovery Today 2010, 15, 171.

[32] a) G. R. Newkome, C. D. Shreiner, Polymer 2008, 49, 1; b) G. R. Newkome, C. Shreiner, Chem. Rev. 2010, 110, 6338 ; c) R. S. Kalhapure, M. K. Kathiravan, K. G. Akamanchi, T. Govender, Pharm. Dev. Technol. 2015, $20,22$.

[33] T. T. Nguyen, M. Baumgarten, A. Rouhanipour, H. J. Rader, I. Lieberwirth, K. Mullen, J. Am. Chem. Soc. 2013, $135,4183$.

[34] G. Caminati, N. J. Turro, D. A. Tomalia, J. Am. Chem. Soc. 1990, 112, 8515.

[35] M. L. Lartigue, B. Donnadieu, C. Galliot, A. M. Caminade, J. P. Majoral, J. P. Fayet, Macromolecules 1997, 30, 7335.

[36] J. Lim, M. Kostiainen, J. Maly, V. C. P. da Costa, O. Annunziata, G. M. Pavan, E. E. Simanek, J Am Chem Soc $2013,135,4660$.

[37] M. A. Mintzer, M. W. Grinstaff, Chem. Soc. Rev. 2011, 40, 173.

[38] M. Arseneault, C. Wafer, J. F. Morin, Molecules 2015, 20, 9263.

[39] V. Maraval, J. Pyzowski, A. M. Caminade, J. P. Majoral, J. Org. Chem. 2003, 68, 6043.

[40] M. V. Walter, M. Malkoch, Chem. Soc. Rev. 2012, 41, 4593.

[41] L. Brauge, G. Magro, A. M. Caminade, J. P. Majoral, J. Am. Chem. Soc. 2001, 123, 6698.

[42] N. Launay, A. M. Caminade, R. Lahana, J. P. Majoral, Angew. Chem. Int. Ed. 1994, 33, 1589.

[43] a) C. U. Herborn, J. Barkhausen, I. Paetsch, P. Hunold, M. Mahler, K. Shamsi, E. Nagel, Radiology 2003, 229, 217; b) C. U. Herborn, M. Schmidt, O. Bruder, E. Nagel, K. Shamsi, J. Barkhausen, Radiology 2004, 233, 567.

[44] A. N. Z. C. T. Registry, A phase 1 dose escalation study to evaluate the safety, tolerability and pharmacokinetics of DTX-SPL8783 (a docetaxel (DTX)-dendrimer conjugate) in patients with advanced solid tumours, www.anzctr.org.au (accessed: December 2016).

[45] W. H. O.-I. C. T. R. Platform, A phase 3, double-blind, multicentre, randomised, placebo-controlled study to determine the efficacy and safety of SPL7013 Gel (VivaGel$\left.{ }^{\circledR}\right)$ to prevent the recurrence of bacterial vaginosis Harmony, http://apps.who.int (accessed:December 2016).

[46] C. F. Price, D. Tyssen, S. Sonza, A. Davie, S. Evans, G. R. Lewis, S. Xia, T. Spelman, P. Hodsman, T. R. Moench, A. Humberstone, J. R. Paull, G. Tachedjian, PLoS One 2011, 6, e24095.

[47] Starpharma, VivaGel® Condom, http://www.starpharma.com/the_vivagel_condom (accessed: January 2017).

[48] J. F. G. A. Jansen, E. M. M. Debrabandervandenberg, E. W. Meijer, Science 1994, $266,1226$.

[49] a) Y. Y. Cheng, N. Man, T. W. Xu, R. Q. Fu, X. Y. Wang, X. M. Wang, L. P. Wen, J. Pharm. Sci. 2007, 96, 595; b) S. Sadekar, G. Thiagarajan, K. Bartlett, D. Hubbard, A. Ray, L. D. McGill, H. Ghandehari, Int. J. Pharm. 2013, 456, 175. [50] H. He, Y. Li, X. R. Jia, J. Du, X. Ying, W. L. Lu, J. N. Lou, Y. Wei, Biomaterials2011, 32, 478.

[51] a) N. Malik, E. G. Evagorou, R. Duncan, Anticancer Drugs 1999, 10, 767; b) I. Haririan, M. S. Alavidjeh, M. R. Khorramizadeh, M. S. Ardestani, Z. Z. Ghane, H. Namazi, Int. J. Nanomed. 2010, 5, 63. 
[52] a) U. H. Sk, D. Dixit, E. Sen, Eur. J. Med. Chem. 2013, 68, 47; b) W. Yang, R. F. Barth, G. Wu, T. Huo, W. Tjarks, M. Ciesielski, R. A. Fenstermaker, B. D. Ross, C. J. Wikstrand, K. J. Riley, P. J. Binns, J. Neuro-Oncol. 2009, 95, 355.

[53] M. Gingras, J. M. Raimundo, Y. M. Chabre, Angew. Chem. Int. Ed. 2007, 46, 1010.

[54] A. K. Patri, J. F. Kukowska-Latallo, J. R. BakerJr., Adv. Drug Delivery Rev. 2005, 57, 2203.

[55] L. M. Kaminskas, V. M. McLeod, C. J. H. Porter, B. J. Boyd, Mol. Pharmaceutics 2012, 9, 355.

[56] D. Shcharbin, A. Janaszewska, B. Klajnert-Maculewicz, B. Ziemba, V. Dzmitruk, I. Halets, S. Loznikova, N. Shcharbina, K. Milowska, M. Ionov, A. Shakhbazau, M. Bryszewska, J. Controlled Release 2014, 181, 40.

[57] a) X. Zhang, J. Zhao, Y. Wen, C. Zhu, J. Yang, F. Yao, Carbohydr. Polym. 2013, 98, 1326; b) C. Kojima, R. Kameyama, M. Yamada, M. Ichikawa, T. Waku, A. Handa, N. Tanaka, Bioconjugate Chem. 2015, 26, 1804.

[58] a) M. Pion, M. J. Serramia, L. Diaz, M. Bryszewska, T. Gallart, F. Garcia, R. Gomez, F. J. de la Mata, M. A. Munoz-Fernandez, Biomaterials 2010, 31, 8749; b) M. Ionov, K. Ciepluch, B. Klajnert, S. Glinska, R. GomezRamirez, F. J. de la Mata, M. A. Munoz-Fernandez, M. Bryszewska, Colloids Surf., B 2013, $101,236$.

[59] a) P. Chanphai, E. Froehlich, J. S. Mandeville, H. A. Tajmir-Riahi, Colloids Surf., B 2016, 150, 168; b) P. Chanphai, L. Bekale, S. Sanyakamdhorn, D. Agudelo, H. A. Tajmir-Riahi, Polymer 2014, 55, 572.

[6o] S. Langereis, A. Dirksen, T. M. Hackeng, M. H. P. van Genderen, E. W. Meijer, New J. Chem. 2007, 31, 1152.

[61] a) A. T. Yordanov, A. L. Lodder, E. K. Woller, M. J. Cloninger, N. Patronas, D. Milenic, M. W. Brechbiel, Nano Lett. 2002, 2, 595; b) Y. J. Fu, D. E. Nitecki, D. Maltby, G. H. Simon, K. Berejnoi, H. J. Raatschen, B. M. Yeh, D. M. Shames, R. C. Brasch, Bioconjugate Chem. 2006, 17, 1043.

[62] a) H. Cai, M. Shen, X. Shi, in Dendrimer-Based Drug Delivery Systems (Ed: Y. Cheng), John Wiley \& Sons, Inc., Hoboken, NJ 2012, pp. 463-478; b) C. Peng, X. Shi, in Dendrimer-Based Drug Delivery Systems (Ed: Y. Cheng), John Wiley \& Sons, Inc., Hoboken, NJ 2012, p. 479.

[63] a) R. Huang, L. Han, J. Li, S. Liu, K. Shao, Y. Kuang, X. Hu, X. Wang, H. Lei, C. Jiang, Biomaterials 2011, 32, 5177; b) L. A. Han, J. F. Li, S. X. Huang, R. Q. Huang, S. H. Liu, X. Hu, P. W. Yi, D. Shan, X. X. Wang, H. Lei, C. Jiang, Biomaterials 2011, 32, 2989; c) H. H. Yan, L. Wang, J. Y. Wang, X. F. Weng, H. Lei, X. X. Wang, L. Jiang, J. H. Zhu, W. Y. Lu, X. B. Wei, C. Li, ACS Nano 2012, 6, 410.

[64] J. Satija, V. V. R. Sai, S. Mukherji, J. Mater. Chem. 2011, 21, 14367.

[65] C. M. Lamy, O. Sallin, C. Loussert, J. Y. Chatton, ACS Nano 2012, 6, 1176.

[66] G. Wu, R. F. Barth, W. Yang, S. Kawabata, L. Zhang, K. Green- Church, Mol. Cancer Ther. 2006, 5, 52.

[67] a) R. F. Barth, G. Wu, W. Yang, P. J. Binns, K. J. Riley, H. Patel, J. A. Coderre, W. Tjarks, A. K. Bandyopadhyaya, B. T. Thirumamagal, M. J. Ciesielski, R. A. Fenstermaker, Appl. Radiat. Isot. 2004, 61, 899; b) W. Yang, R. F. Barth, G. Wu, S. Kawabata, T. J. Sferra, A. K. Bandyopadhyaya, W. Tjarks, A. K. Ferketich, M. L. Moeschberger, P. J. Binns, K. J. Riley, J. A. Coderre, M. J. Ciesielski, R. A. Fenstermaker, C. J. Wikstrand, Clin. Cancer Res. 2006, 12, 3792; C) G. Wu, W. Yang, R. F. Barth, S. Kawabata, M. Swindall, A. K. Bandyopadhyaya, W. Tjarks, B. Khorsandi, T. E. Blue, A. K. Ferketich, M. Yang, G. A. Christoforidis, T. J. Sferra, P. J. Binns, K. J. Riley, M. J. Ciesielski, R. A. Fenstermaker, Clin. Cancer Res. 2007, 13, 1260.

[68] A. O. Elzoghby, M. M. Abd-Elwakil, K. Abd-Elsalam, M. T. Elsayed, Y. Hashem, O. Mohamed, Curr. Pharm. Des. 2016, 22, 3305. [69] L. A. Lambert, Biochim. Biophys. Acta 2012, 1820, 244. [70] R. Q. Huang, Y. H. Qu, W. L. Ke, J. H. Zhu, Y. Y. Pei, C. Jiang, FASEB J 2007, 21, 1117.

[71] a) R. Huang, W. Ke, Y. Liu, C. Jiang, Y. Pei, Biomaterials 2008, 29, 238; b) R. Huang, W. Ke, L. Han, Y. Liu, K. Shao, L. Ye, J. Lou, C. Jiang, Y. Pei, J. Cereb. Blood Flow Metab. 2009, 29, 1914. [72] J. H. Lee, J. A. Engler, J. F. Collawn, B. A. Moore, Eur. J. Biochem. 2001, 268, 2004. 
[73] a) W. Ke, K. Shao, R. Huang, L. Han, Y. Liu, J. Li, Y. Kuang, L. Ye, J. Lou, C. Jiang, Biomaterials 2009, 30, 6976; b) S. Huang, J. Li, L. Han, S. Liu, H. Ma, R. Huang, C. Jiang, Biomaterials 2011, 32, 6832.

[74] Y. Liu, R. Huang, L. Han, W. Ke, K. Shao, L. Ye, J. Lou, C. Jiang, Biomaterials 2009, 30, 4195.

[75] a) R. Huang, L. Han, J. Li, F. Ren, W. Ke, C. Jiang, Y. Pei, J. Gene Med. 2009, 11, 754; b) R. Huang, W. Ke, L. Han, J. Li, S. Liu, C. Jiang, Biomaterials 2011, 32, 2399.

[76] S. Somani, C. Dufes, Nanomedicine (London, UK) 2014, 9, 2403.

[77] C. Z. Bai, S. Choi, K. Nam, S. An, J. S. Park, Int. J. Pharm. 2013, 445, 79.

[78] A. Bertero, A. Boni, M. Gemmi, M. Gagliardi, A. Bifone, G. Bardi, Nanotoxicology 2014, 8, 158.

[79] F. Vidal, P. Vasquez, C. Diaz, D. Nova, J. Alderete, L. Guzman, Mol. Pharmaceutics 2016, 13, 3395.

[80] A. J. Salgado, J. M. Oliveira, R. P. Pirraco, V. H. Pereira, J. S. Fraga, A. P. Marques, N. M. Neves, J. F. Mano, R.

L. Reis, N. Sousa, Macromol. Biosci. 2010, 10, 1130.

[81] S. D. Santos, K. L. Lambertsen, B. H. Clausen, A. Akinc, R. Alvarez, B. Finsen, M. J. Saraiva, J. Neurochem. 2010, 115, 1434 .

[82] A. Canazza, L. Minati, C. Boffano, E. Parati, S. Binks, Front. Neurol. 2014, 5, 19.

[83] S. An, Y. Y. Kuang, T. Shen, J. F. Li, H. J. Ma, Y. B. Guo, X. He, C. Jiang, Biomaterials 2013, 34, 8949.

[84] S. M. Abraham, T. Lawrence, A. Kleiman, P. Warden, M. Medghalchi, J. Tuckermann, J. Saklatvala, A. R. Clark, J. Exp. Med. 2006, 203, 1883.

[85] J. S. Choi, K. S. Ko, J. S. Park, Y. H. Kim, S. W. Kim, M. Lee, Int. J. Pharm. 2006, 320, 171.

[86] D. A. Patel, J. E. Henry, T. A. Good, Brain Research 2007, 1161, 95.

[87] Y. B. Lim, C. E. Mays, Y. Kim, W. B. Titlow, C. Ryou, Biomaterials 2010, 31, 2025.

[88] J. M. McCarthy, B. R. Moreno, D. Filippini, H. Komber, M. Maly, M. Cernescu, B. Brutschy, D. Appelhans, M. S. Rogers, Biomacromolecules 2013, 14, 27.

[89] A. Canestri, F. X. Lescure, S. Jaureguiberry, A. Moulignier, C. Amiel, A. G. Marcelin, G. Peytavin, R. Tubiana, G. Pialoux, C. Katlama, Clin. Infect. Dis. 2010, 50, 773.

[90] R. F. Barth, A. H. Soloway, Mol. Chem. Neuropathol. 1994, 21, 139.

[91] M. V. Backer, T. I. Gaynutdinov, V. Patel, A. K. Bandyopadhyaya, B. T. Thirumamagal, W. Tjarks, R. F. Barth, K. Claffey, J. M. Backer, Mol. Cancer Ther. 2005, 4, 1423.

[92] H. M. Teow, Z. Y. Zhou, M. Najlah, S. R. Yusof, N. J. Abbott, A. D'Emanuele, Int. J. Pharm. 2013, 441, 701. [93] S. An, K. Nam, S. Choi, C. Z. Bai, Y. Lee, J. S. Park, Int. J. Nanomed. 2013, 8, 821.

[94] A. Agrawal, D. H. Min, N. Singh, H. H. Zhu, A. Birjiniuk, G. von Maltzahn, T. J. Harris, D. Y. Xing, S. D. Woolfenden, P. A. Sharp, A. Charest, S. Bhatia, ACS Nano 2009, 3, 2495.

[95] a) C. S. Ahuja, M. Fehlings, Stem Cells Transl. Med. 2016, 5, 914; b) L. R. Pires, A. P. Pego, Regen. Biomater. 2015, 2, 203.

[96] S. R. Cerqueira, J. M. Oliveira, N. A. Silva, H. Leite-Almeida, S. Ribeiro-Samy, A. Almeida, J. F. Mano, N. Sousa, A. J. Salgado, R. L. Reis, Small 2013, 9, 738.

[97] H. H. Yan, J. Y. Wang, P. W. Yi, H. Lei, C. Y. Zhan, C. Xie, L. L. Feng, J. Oian, J. H. Zhu, W. Y. Lu, C. Li, Chem. Commun. 2011, 47, 8130.

[98] L. Albertazzi, M. Brondi, G. M. Pavan, S. S. Sato, G. Signore, B. Storti, G. M. Ratto, F. Beltram, PLoS One 2011, 6, e28450. [99] A. Shakhbazau, M. Mishra, T. H. Chu, C. Brideau, K. Cummins, S. Tsutsui, D. Shcharbin, J. P. 
Majoral, S. Mignani, M. Blanchard- Desce, M. Bryszewska, V. W. Yong, P. K. Stys, J. van Minnen, Macromol. Biosci. $2015,15,1523$

[100] W. M. Pardridge, J. Cereb. Blood Flow Metab. 2012, 32, 1959.

[101] a) T. C. Heiden, E. Dengler, W. J. Kao, W. Heideman, R. E. Peterson, Toxicol. Appl. Pharmacol. 2007, 225, 70; b) N. A. Stasko, C. B. Johnson, M. H. Schoenfisch, T. A. Johnson, E. L. Holmuhamedov, Biomacromolecules 2007, 8, 3853 ; c) K. Greish, G. Thiagarajan, H. Herd, R. Price, H. Bauer, D. Hubbard, A. Burckle, S. Sadekar, T. Yu, A. Anwar, A. Ray, H. Ghandehari, Nanotoxicology 2012, 6, 713.

[102] P. Kesharwani, R. K. Tekade, N. K. Jain, Pharm. Res. 2015, 32, 1438.

[103] a) T. Okuda, S. Kawakami, T. Maeie, T. Niidome, F. Yamashita, M. Hashida, J. Controlled Release 2006, 114, 69 ; b) A. S. Chauhan, P. V. Diwan, N. K. Jain, D. A. Tomalia, Biomacromolecules 2009, 10, 1195; c), 1535A. S. Chauhan, N. K. Jain, P. V. Diwan, Proc. R. Soc. A, 2010, 466; d) B. Ziemba, A. Janaszewska, K. Ciepluch, M. Krotewicz, W. A. Fogel, D. Appelhans, B. Voit, M. Bryszewska, B. Klajnert, J. Biomed. Mater. Res., Part A 2011, 99, 261.

[104] a) M. Labieniec, O. Ulicna, O. Vancova, R. Glowacki, K. Sebekova, E. Bald, T. Gabryelak, C. Watala, Int. J. Pharm. 2008, 364, 142; b) C. Li, H. Liu, Y. Sun, H. Wang, F. Guo, S. Rao, J. Deng, Y. Zhang, Y. Miao, C. Guo, J. Meng, X. Chen, L. Li, D. Li, H. Xu, H. Wang, B. Li, C. Jiang, J. Mol. Cell Biol. 2009, 1, 37; C) C. F. Jones, R. A. Campbell, A. E. Brooks, S. Assemi, S. Tadjiki, G. Thiagarajan, C. Mulcock, A. S. Weyrich, B. D. Brooks, H. Ghandehari, D. W. Grainger, ACS Nano 2012, 6, 9900.

[105] a) A. Mecke, S. Uppuluri, T. M. Sassanella, D. K. Lee, A. Ramamoorthy, J. R. Baker Jr., B. G. Orr, M. M. Banaszak Holl, Chem. Phys. Lipids 2004, 132, 3; b) I. J. Majoros, C. R. Williams, A. C. Becker, J. R. Baker Jr., J. Comput. Theor. Nanosci. 2009, 6, 1430.

[106] K. Jain, P. Kesharwani, U. Gupta, N. K. Jain, Int. J. Pharm. 2010, 394, 122.

[107] a) N. Malik, R. Wiwattanapatapee, R. Klopsch, K. Lorenz, H. Frey, J. W. Weener, E. W. Meijer, W. Paulus, R. Duncan, J. Controlled Release 2000, 65, 133; b) S. Sadekar, A. Ray, M. Janat-Amsbury,

C. M. Peterson, H. Ghandehari, Biomacromolecules 2011, 12, 88.

[108] a) L. M. Kaminskas, B. J. Boyd, C. J. Porter, Nanomedicine (London, UK) 2011, 6, 1063; b) W. Wijagkanalan, S. Kawakami, M. Hashida, Pharm. Res. 2011, 28, 1500.

[109] C. Kojima, C. Regino, Y. Umeda, H. Kobayashi, K. Kono, Int. J. Pharm. 2010, 383, 293.

[110] a) S. Lowe, N. M. O'Brien-Simpson, L. A. Connal, Polym. Chem. 2015, 6, 198; b) K. C. Liv, Y. Yeo, Mol. Pharmaceutics 2013, 10, 1695 .

[111] a) R. Luxenhofer, Y. C. Han, A. Schulz, J. Tong, Z. J. He, A. V. Kabanov, R. Jordan, Macromol. Rapid Comm. 2012, 33, 1613; b) K. Kempe, S. Onbulak, U. S. Schubert, A. Sanyal, R. Hoogenboom, Polymer Chemistry 2013, 4, 3236.

[112] A. C. Engler, X. Y. Ke, S. J. Gao, J. M. W. Chan, D. J. Coady, R. J. Ono, R. Lubbers, A. Nelson, Y. Y. Yang, J. L. Hedrick, Macromolecules 2015, 48, 1673.

[113] P. Kesharwani, R. K. Tekade, V. Gajbhiye, K. Jain, N. K. Jain, Nanomedicine 2011, 7, 295.

[114] S. P. Mukherjee, F. M. Lyng, A. Garcia, M. Davoren, H. J. Byrne, Toxicol. Appl. Pharmacol. 2010, 248, 259.

[115] V. Leiro, J. P. Garcia, H. Tomas, A. P. Pego, Bioconjugate Chem. 2015, 26, 1182.

[116] C. D. Lopes, M. Gomez-Lazaro, A. P. Pego, Nanomedicine (London, UK) 2015, 10, 2307.

[117] L. Fulop, I. M. Mandity, G. Juhasz, V. Szegedi, A. Hetenyi, E. Weber, Z. Bozso, D. Simon, M. Benko, Z. Kiraly, T. A. Martinek, PLoS One 2012, 7, e39485. [118] C. L. Waite, C. M. Roth, Bioconjugate Chem. 2009, 20, 1908. 
[119] J. B. Kim, J. S. Choi, K. Nam, M. Lee, J. S. Park, J. K. Lee, J. Controlled Release 2006, 114, 110.

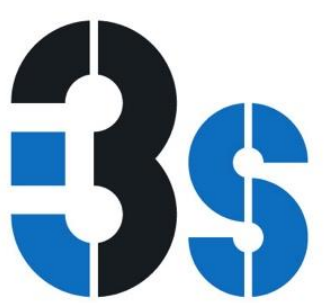

Rua Alfredo Allen, 208 4200-135 Porto 


\section{Biographies}

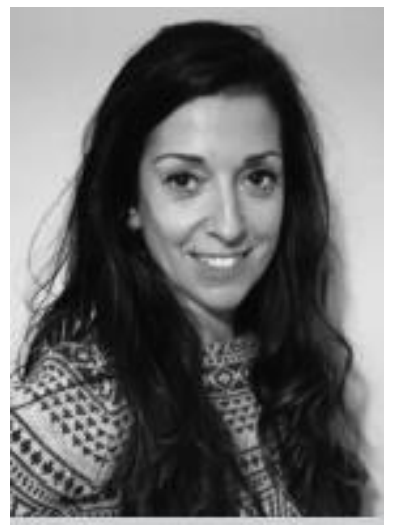

Victoria Leiro (Ph.D.) is a post - doctoral researcher in the $\mathrm{nBTT}-$ nanoBiomaterials for Targeted Therapies Group at INEB and i3S. After finishing her Ph.D. in Chemistry (Organic Chemistry), her research focused on the design and synthesis of new biodegradable dendritic nanomaterials to act as versatile vectors in several biomedical applications, as well as on their application in the delivery of different therapeutic nucleic acids to the peripheral and central nervous system, with the aim of promoting neuroregeneration and neuroprotection.

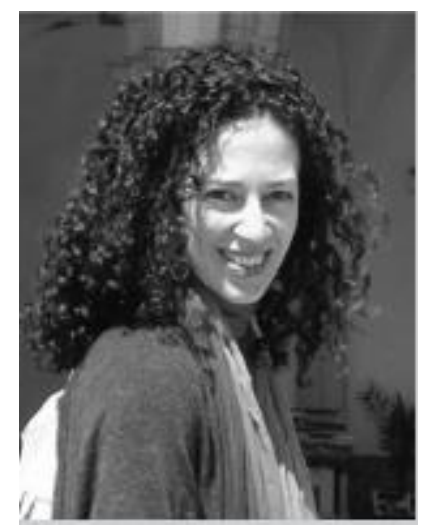

Sofia Duque Santos (Ph.D.) is a post - doctoral researcher in the nBTT-nanoBiomaterials for Targeted Therapies Group at INEB and i3S. Her research interests fall in the area of neuroscience. She completed a Ph.D. focused on neurodegenerative disease of the peripheral nervous system and then did post - doctoral studies on the ischemic brain. Her present research interests are in pre clinical studies of neuroprotective approaches based on nanomedicine for application in stroke. 


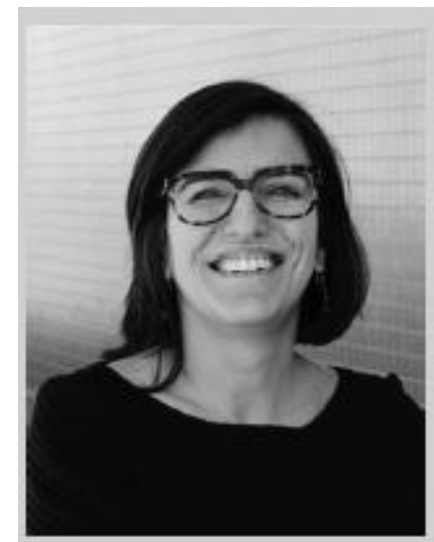

Ana Paula Pêgo (Ph.D.) is the Coordinator of the nBTTnanoBiomaterials for Targeted Therapies Group at INEB and i3S. By using nanomedicine strategies, her team aims to provide an in situ, targeted approach to the required signals to promote nervous tissue regeneration. The research on new nanobiomaterials for application in neurosciences includes the development of new polymers for the design of alternative vectors to viruses for efficient nucleic acid delivery to neuronal cells and preparation of nerve grafts for spinal cord injury treatment. 